\title{
Investigation on Wear Characteristics of Cemented Carbide Tools in Finish Turning Spherical Shells of Pure Iron
}

\section{Yu Chen}

China Academy of Engineering Physics

Jinxing Kong ( $\nabla$ kjxmc106@163.com )

China Academy of Engineering Physics

Zhenyu Zhang

Dalian University of Technology https://orcid.org/0000-0002-2393-520X

Dongxing Du

China Academy of Engineering Physics

\section{Research Article}

Keywords: Pure iron, Spherical shell turning, End face turning, Notch wear, Flank wear

Posted Date: April 21st, 2021

DOI: https://doi.org/10.21203/rs.3.rs-424556/v1

License: (a) (i) This work is licensed under a Creative Commons Attribution 4.0 International License. Read Full License

Version of Record: A version of this preprint was published at The International Journal of Advanced Manufacturing Technology on January 13th, 2022. See the published version at https://doi.org/10.1007/s00170-021-08441-0. 


\section{Investigation on Wear Characteristics of Cemented Carbide Tools in Finish Turning Spherical Shells of Pure Iron}

Yu Chen ${ }^{1}$, Jinxing Kong ${ }^{1 *}$, Zhenyu Zhang ${ }^{2 *}$, Dongxing $\mathrm{Du}^{1}$

1. Institute of Mechanical Manufacturing Technology, China Academy of Engineering Physics, Mianyang, Sichuan 621900, People's Republic of China

2. Key Laboratory for Precision and Non-traditional Machining Technology of Ministry of Education, Dalian University of Technology, Dalian 116024, China

*Corresponding author. E-mail address: kjxmc106@163.com

** Corresponding author. E-mail address: zzy@dlut.edu.cn

Abstract: A thin-walled spherical shell made of pure iron material is a key part of precision physical experiments. Tool wear is an important factor restricting its geometric accuracy. And tool wear characteristics of curved surface parts are significantly different from those of single-point turning due to the movement of the contact point between the tool and the workpiece. Hence, this article takes the pure iron spherical shell as the research object, which is aimed at investigating the formation mechanisms of flank wear land. Tool wear characteristics are compared between spherical shell turning and end face turning. The results show that uniform flank wear land and notable notch wear occur when turning end face, but notch wear disappears and only flank wear land exists when turning spherical shell. Based on major notch position and minor notch position, a mathematical model is developed to explain formation mechanisms of flank wear land during turning spherical shell of pure iron materials. Theoretical and experimental results show that flank wear land results from the major and minor notch movement. Spherical shell turning and end face turning have the same wear mechanisms, mainly composed of adhesive wear, diffusion wear and oxidation wear.

Key words: Pure iron, Spherical shell turning, End face turning, Notch wear, Flank wear

\section{Introduction}

Pure iron materials are widely used in industries such as national defense, energy, and power electronics due to its excellent plasticity, impact resistance, and electromagnetic properties. The thin-walled spherical shell made of pure iron material is a key part of precision physical experiment research such as detonation and shock wave[1-3]. To eliminate the influence of machining errors on the accuracy, reliability, and repeatability of the experimental results, higher processing technology requirements are put forward for the shape accuracy, position accuracy, and surface quality of the key parts in the experimental device. However, pure iron is also a typical difficult-to-machine material due to its high plasticity and toughness[3]. Work hardening and plasticity deformation tend to be serious, and pure iron is easy to be adhered on tool face to form built-up layer (BUL) and built-up edge (BUE), which leads to rapid tool wear. In the process of manufacturing large-size pure iron curved components used in precision physical tests, it is found that tool wear is an important factor that restricts its surface quality and contour accuracy[4-7].

At present, some researchers have carried out investigations on tool wear in machining pure iron materials. Kong et al.[8] observed two V-shaped notches located at the major and minor cutting edge respectively, and uniform flank wear land in the process of turning pure iron materials. They thought that the formation mechanisms of notch wear were the comprehensive outcomes of adhesive wear, diffusion wear and oxidation wear. Tao et al.[9] found the wear morphology of carbide tools was mainly crater, accompanied by boundary wear on the flank face when cutting pure iron. They thought the main wear mechanisms of carbide tools were adhesive 
wear, abrasive wear and oxidation wear. Liu et al.[10] believed that notch wear was a significant characteristic and determined the tool life in cutting pure iron, and studied the wear laws of flank wear, major notch wear and minor notch wear under four types of cooling/lubrication conditions. Notch wear is a significant wear characteristic when cutting pure iron, nickel-based alloys, low carbon steel and other materials with strong work hardening tendency. Many researchers have studied the location and formation mechanisms of notch wear. Xiao and He et al.[11,12] reported that the practical DOC notch wear location was larger than the theoretical location because of the side flow of plastic deformation. They thought that the saw-tooth-shaped chip edge and the side cutting burr on the workpiece resulted in notch wear. Kong et al.[8] also believed the position of notch wear was not actually at the depth of the cut line, but outside the cutting area. They thought the formation mechanisms of notch wear in turning pure iron material are the comprehensive results of adhesion wear, diffusion wear, and oxidation wear. Bushlya et al.[13] thought that major notch was located at the depth-of-cut extremity, and minor notch was related to the defects left on the surface during machining. They revealed DOC notch was formed due to tool stress state and burr formation, and defects of side flow and plastic flow left on the machined surface determined the minor notch wear. Ezugwu et al.[14] revealed the hardened layer beneath the workpiece surface was the key causation of notch wear. Brandt $G$ and Olovsjö et al[15,16] observed the notch wear was mainly caused by seizure and pulling out of tool material. Zhuang et al.[17] found notch wear located in the hardened layer of the workpiece, and proposed a notch wear model based on the depth of hardening and the notch wear geometry. Kasim et al.[18] thought notch wear typically located near the DOC line, and proposed a notch wear location prediction model in ball nose end milling of Inconel 718.

The single-point cutting tests are widely used in tool wear mechanisms research[19]. The goal is to ensure that the contact point between the tool and the workpiece remains unchanged, which is conducive to obtaining accurate tool wear modes and the law of influence of process parameters on tool wear. Since the relative position of the tool with respect to the contact area on the workpiece varies continuously, it can be inferred that the notch wear position will also move. Wear modes and wear laws will be significantly different between curved surface parts cutting and single-point cutting. However, there has been no research on tool wear characteristics for cutting high-plasticity and high-toughness pure iron curved parts.

Therefore, this research focused on exploring tool wear characteristics and wear mechanisms. The tool wear characteristics of cutting pure iron end faces and cutting pure iron spherical shells are contrasted in this paper. The evolutionary laws are obtained for flank wear, cutting edge radius, cutting edge retraction and tool nose radius. Based on notch wear position of turning pure iron end faces, the formation mechanism of flank wear land is analyzed during turning spherical shells. This will lay the foundation for improving tool life, machining surface quality and machining accuracy during cutting pure iron curved surface parts.

\section{Materials and experimental methods}

Pure iron materials were utilized as workpiece materials, which were forged at room temperature and then treated at $700{ }^{\circ} \mathrm{C}$ for $2 \mathrm{~h}$. Table 1 shows the chemical compositions of pure iron. Pure iron end faces (diameter $160 \mathrm{~mm}$, thickness $20 \mathrm{~mm}$ )) and pure iron spherical shells (SR $100 \mathrm{~mm}$, wall thickness $10 \mathrm{~mm}$ ) are two types of test workpieces for tool wear experiments.

Turning tests are carried out in CNC lathe CK6150S/1000(made in china) with a maximum 
spindle speed of $1600 \mathrm{r} / \mathrm{min}$. The types of insert and holder are Kennametal DCGT11T302 HP KC5010 and SDJCL2020K11 respectively in the present work. Machining tests are performed under the same cutting parameters on the pure iron end face and pure iron spherical shell. Cutting parameters are as follows: spindle speed $n=200 \mathrm{r} / \mathrm{min}$, feed rate $\mathrm{f}=0.08 \mathrm{~mm} / \mathrm{r}$, and depth of cut $\mathrm{a}_{\mathrm{p}}=0.1 \mathrm{~mm}$.

Table 1 the chemical compositions of pure iron

\begin{tabular}{cccccccccc}
\hline $\mathrm{Fe}$ & $\mathrm{C}$ & $\mathrm{Si}$ & $\mathrm{Mn}$ & $\mathrm{Ni}$ & $\mathrm{S}$ & $\mathrm{Cr}$ & $\mathrm{Cu}$ & $\mathrm{P}$ & $\mathrm{Al}$ \\
\hline$>99.8$ & 0.013 & 0.028 & 0.029 & 0.035 & 0.02 & 0.02 & 0.034 & 0.0072 & 0.0023 \\
\hline
\end{tabular}

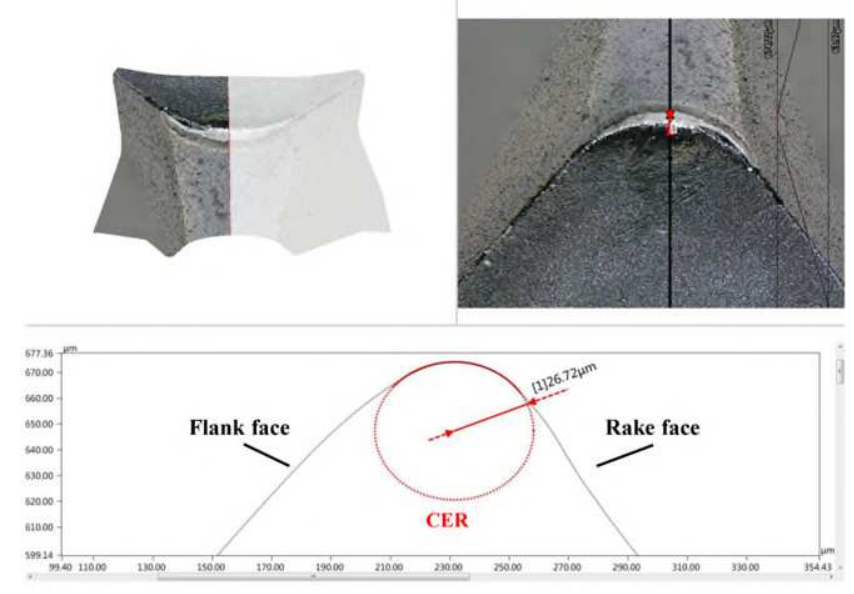

Fig. $12 \mathrm{D}$ profile of secondary cutting edge obtained by microscope.

Flank wear VB is usually adopted to represent the wear of cutting edge. To fully understand the wear of cutting edge, this work focuses on flank wear, cutting edge radius(CER), tool nose radius and cutting edge retraction of cutting pure iron spherical shells. Flank wear and notch wear are used to quantify tool wear in pure iron end face cutting. In the experiment, cutting edge wear is periodically examined off-line on the Keyence microscope. At first, the 3D profile of the cutting edge is obtained by using the depth composition function of the microscope. Then, 2D profile of the cutting edge is extracted by the microscope's internal software based on the 3D profile and CER is measured, as shown in Fig. 1. In Fig. 2(a), the intersection point of flank face and rake face is ideal tool tip(a). $\mathrm{x}_{1}$ is the distance between the ideal tool tip and new tool tip, and $\mathrm{x}$ is the distance between the ideal tool tip and worn tool tip. Cutting edge retraction is the difference between $x$ and $x_{1}$. The value of $x$ and $x_{1}$ is got by $2 D$ profile of the cutting edge extracted by Keyence microscope, as shown in Fig. 2(b). Tool nose radius on rake face, flank wear VB and notch wear are also measured with the microscope. The adherent pure iron materials on the cutting tools are corroded by using a $10 \%$ dilute nitric acid $\left(\mathrm{HNO}_{3}\right)$ before tool wear is measured. Tool wear mechanisms are analyzed using a scanning electron microscopy (SEM) equipped with an Energy dispersive spectrometer (EDS) instrument. 

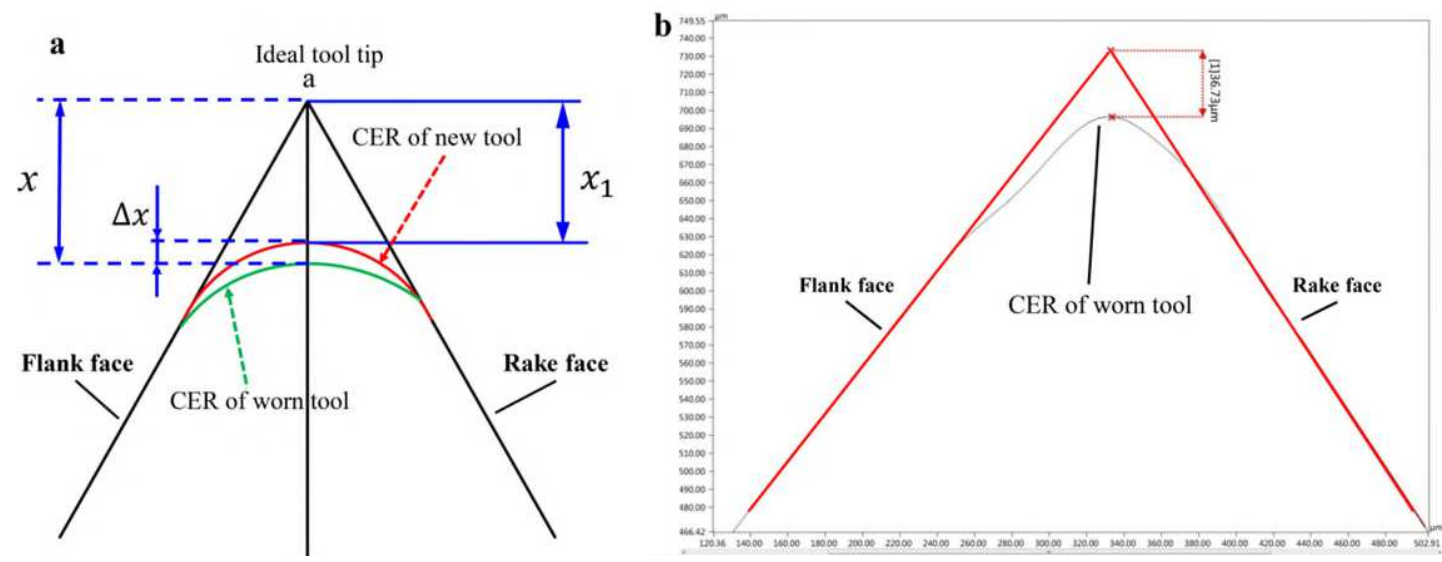

Fig. 2 (a) Schematic of cutting edge retraction measurement and (b) distance between the ideal tool tip and actual tool tip

\section{Results and discussion}

\subsection{Tool wear modes}

A comparison of tool wear modes in the cutting tools is shown in Fig. 3 when turning pure iron end faces and pure iron spherical shells at the same magnification of the microscope. These images are tool wear morphology after removing adherent materials by dilute nitric acid, and demonstrate the difference of wear modes. In Fig 3(a), major notch, minor notch and flank wear on flank face are observed significantly with increasing cutting time during turning end face of pure iron materials, and major notch wear is less than minor notch wear. Because of its larger values, two narrow $\mathrm{V}$-shaped notches are the principal wear modes in turning end face of pure iron Minor notch wear not only plays a significant role in reaching tool failure but also determines the machined surface integrity. However, only wear land occures on the flank face and conspicuous notch wear disappears in Fig 3(b) during turning spherical shell. The size of flank wear land is used as a tool life criterion for turning spherical shell of pure iron materials.

The area of the tool involved in cutting process doesn't change when cutting the end face. Fig. 4(a) shows point $\mathrm{A}$ and $\mathrm{B}$ on the tool are the theoretical locations of major notch and minor notch respectively. Point A and B at the tool-workpiece contact boundary are always fixed in cutting process. Yet at Fig. 4(b), point $\mathrm{C}$ and $\mathrm{D}$ at the tool-workpiece contact boundary also travel around the tool nose during cutting the spherical shell. Point $\mathrm{C}$ and D are also theoretical notch wear positions, so major notch and minor notch also will move. Therefore, tool movement is the cause of the difference in wear modes. 
(a)

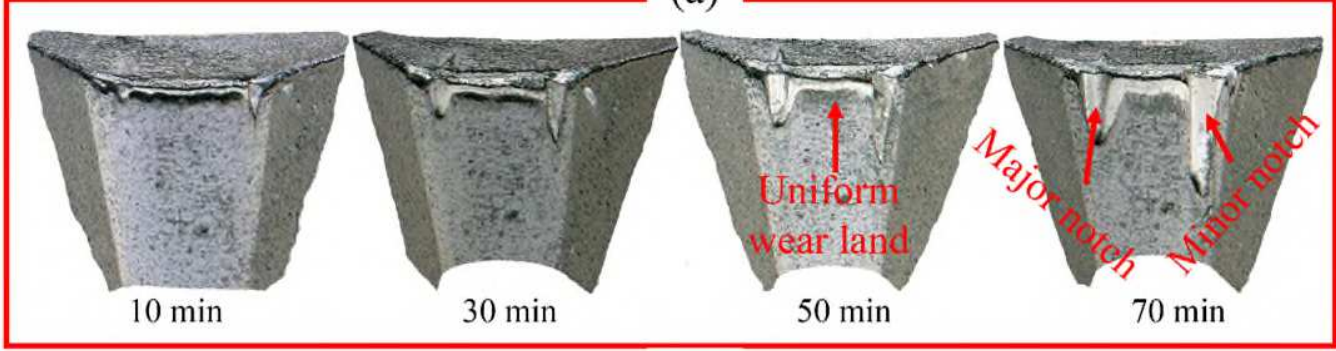

(b)

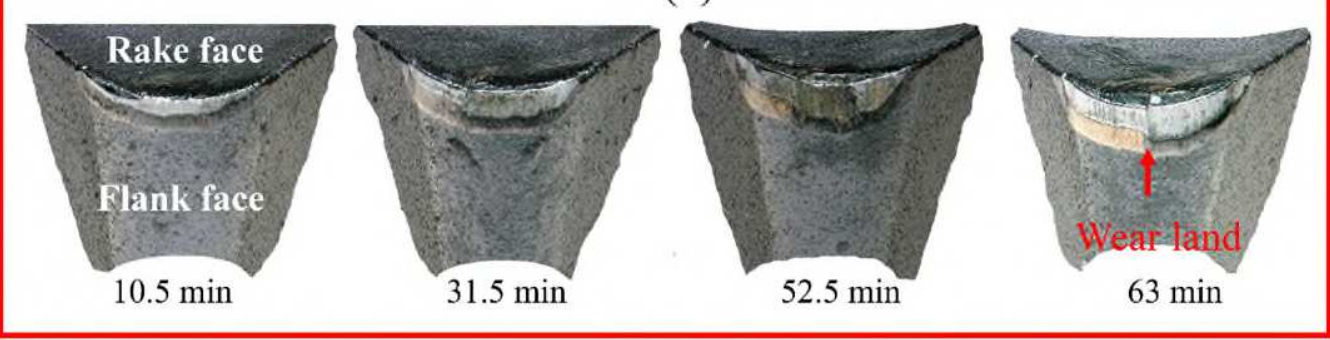

Fig. 3 Comparison of tool wear under different cutting methods, (a) end face turning, (b) spherical shell turning
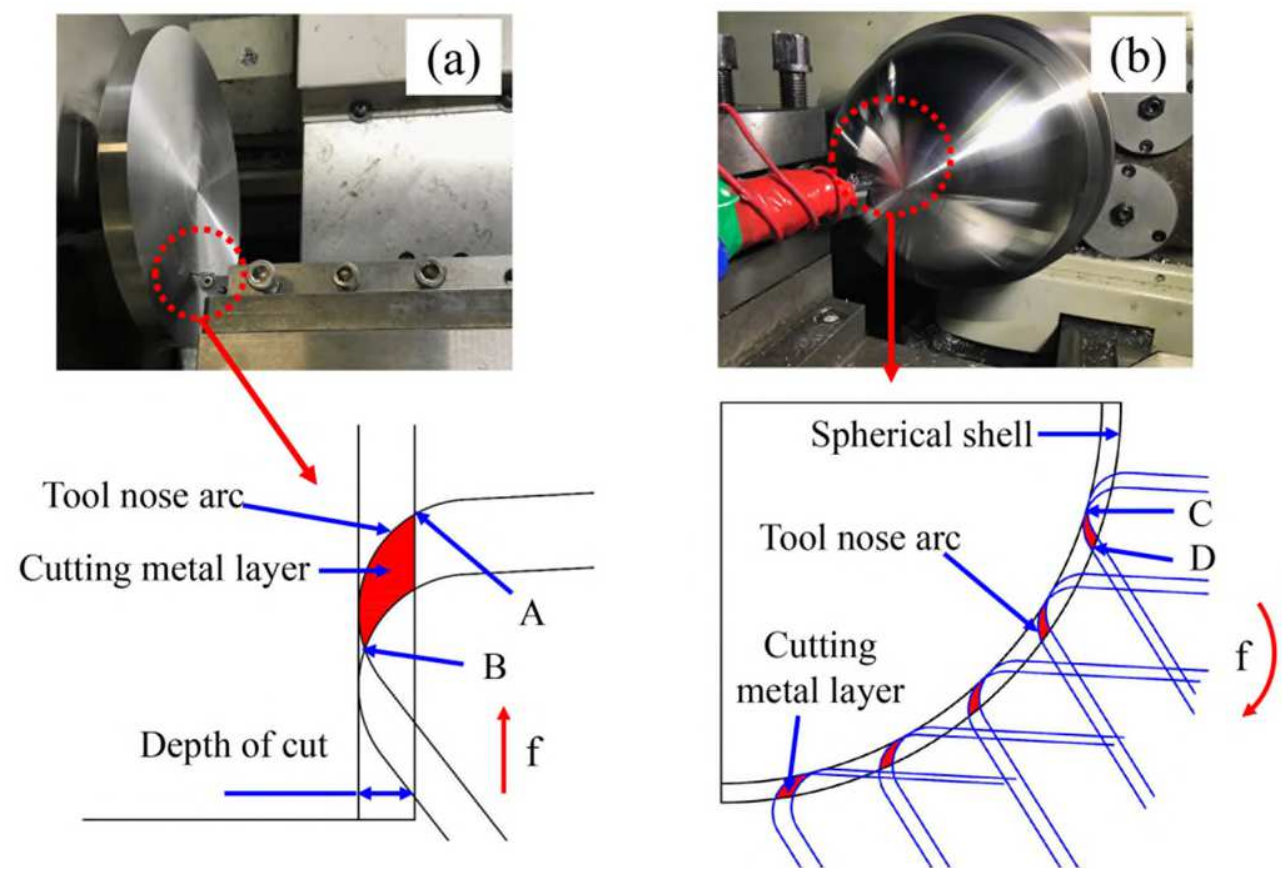

Fig. 4 Schematic of turning end face (a) and turning spherical shell (b)

\subsection{Wear characteristic formation mechanisms in finish turning pure iron curved surface}

The cutting contact area doesn't move within the feed per revolution, so turning spherical shell can be regarded as several end face turning. The notch wear at the cutting boundary is key wear mode when cutting pure iron end face, but notch wear disappears in cutting the spherical shell due to tool movement. It can be assumed that major notch and minor notch will move along the cutting edge in turning the spherical shell. Coordinate diagrams are developed to solve the mathematical model of major notch movement and minor notch movement along flank face, as shown in Fig. 5. Major notch and minor notch occur at the contact boundary of tool-workpiece.

According to Fig. 5, point $\mathrm{M}$ is the theoretical position of major notch. It is derived as 
follows:

Coordinate transformation formula between xoy coordinate system and $x^{\prime} o^{\prime} y^{\prime}$ coordinate system is as follows:

$$
\begin{aligned}
& x=x^{\prime}-R^{\prime} \cos \theta \\
& y=y^{\prime}-R^{\prime} \sin \theta,
\end{aligned} \quad R^{\prime}=R+r_{0}
$$

Where $r_{0}$ is the original corner radius, $\mathrm{R}$ is the radius of spherical shell outer circle after cutting. $\theta$ is the angle between the straight line passing through the center of the tool nose arc and the coordinate origin and $\mathrm{X}$ axis.

Equation of spherical shell outer circle and the tool nose arc in xoy coordinate system can be expressed as follows respectively:

$$
\begin{aligned}
& \left(x+\cos \theta \cdot R^{\prime}\right)^{2}+\left(y+\sin \theta \cdot R^{\prime}\right)^{2}=R_{1}^{2} \\
& x^{2}+y^{2}=r_{0}^{2}
\end{aligned}
$$

Where $\mathrm{R}_{1}$ is the radius of original spherical shell outer circle.

Combining Eq. (2) and Eq. (3), major notch position can be calculated as :

$$
\begin{aligned}
& x_{1}=\frac{M \cdot \cos \theta-\sqrt{(M \cdot \cos \theta)^{2}-M-\left(2 r_{0} R^{\prime} \cdot \sin \theta\right)^{2}}}{2 R^{\prime}} \\
& y_{1}=\sqrt{r_{0}^{2}-\frac{M \cdot \cos \theta-\sqrt{(M \cdot \cos \theta)^{2}-M-\left(2 r_{0} R^{\prime} \cdot \sin \theta\right)^{2}}}{2 R^{\prime}}} \\
& M=r_{0}^{2}+R^{\prime 2}-R_{1}^{2}
\end{aligned}
$$

$\left(x_{1}, y_{1}\right)$ is the theoretical position of the major notch in the xoy coordinate system. It can be seen that the position of the major notch changes with the angle $\theta$.

Minor notch occurs at point N. According to Fig. 3, the theoretical position of minor notch is derived as follows:

Equation of the tool nose arc in $x^{\prime} o^{\prime} y^{\prime}$ coordinate system is as follws:

$$
\left(x^{\prime}-\cos \theta \cdot R^{\prime}\right)^{2}+\left(y^{\prime}-\sin \theta \cdot R^{\prime}\right)^{2}=r_{0}^{2}
$$

The straight line through the center of tool nose arc and the origin of the coordinates in $x^{\prime} o^{\prime} y^{\prime}$ coordinate system can be expressed as follows :

$$
y^{\prime}=\tan \left(\theta-\frac{f}{2 R^{\prime}}\right) \cdot x^{\prime}
$$

Combining Eq. (5) and Eq. (6), we obtain 
$x^{\prime}=\frac{\left(2 R^{\prime} \tan \left(\theta-\frac{f}{2 R^{\prime}}\right) \cdot \sin \theta+2 R^{\prime} \cos \theta\right)-\sqrt{\left(2 R^{\prime} \tan \left(\theta-\frac{f}{2 R^{\prime}}\right) \cdot \sin \theta+2 R^{\prime} \cos \theta\right)^{2}-4\left(1+\tan ^{2}\left(\theta-\frac{f}{2 R^{\prime}}\right)\right) \cdot\left(R^{\prime 2}-r_{0}^{2}\right)}}{2\left(1+\tan ^{2}\left(\theta-\frac{f}{2 R^{\prime}}\right)\right)}$
$y^{\prime}=\tan \left(\theta-\frac{f}{2 R^{\prime}}\right) \cdot \frac{\left(2 R^{\prime} \tan \left(\theta-\frac{f}{2 R^{\prime}}\right) \cdot \sin \theta+2 R^{\prime} \cos \theta\right)-\sqrt{\left(2 R^{\prime} \tan \left(\theta-\frac{f}{2 R^{\prime}}\right) \cdot \sin \theta+2 R^{\prime} \cos \theta\right)^{2}-4\left(1+\tan ^{2}\left(\theta-\frac{f}{2 R^{\prime}}\right)\right) \cdot\left(R^{\prime 2}-r_{0}^{2}\right)}}{2\left(1+\tan ^{2}\left(\theta-\frac{f}{2 R^{\prime}}\right)\right)}$

$\left(x^{\prime}, y^{\prime}\right)$ is the theoretical position of the minor notch in the $x^{\prime} o^{\prime} y^{\prime}$ coordinate system.

To simplify the equation, $A=\tan \left(\theta-\frac{f}{2 R^{\prime}}\right)$ is brought into Eq. (7). Then, according to Eq. (1), the theoretical position of minor notch in xoy coordinate system is derived as follows:

$$
\begin{aligned}
& x=\frac{\left(R^{\prime 2}-r_{0}^{2}\right)}{R^{\prime}(A \cdot \sin \theta+\cos \theta)-\sqrt{R^{\prime 2}(A \cdot \sin \theta+\cos \theta)^{2}-\left(1+A^{2}\right) \cdot\left(R^{\prime 2}-r_{0}^{2}\right)}}-R^{\prime} \cos \theta \\
& y=\frac{A\left(R^{\prime 2}-r_{0}^{2}\right)}{R^{\prime}(A \cdot \sin \theta+\cos \theta)-\sqrt{R^{\prime 2}(A \cdot \sin \theta+\cos \theta)^{2}-\left(1+A^{2}\right) \cdot\left(R^{\prime 2}-r_{0}^{2}\right)}}-R^{\prime} \sin \theta
\end{aligned}
$$

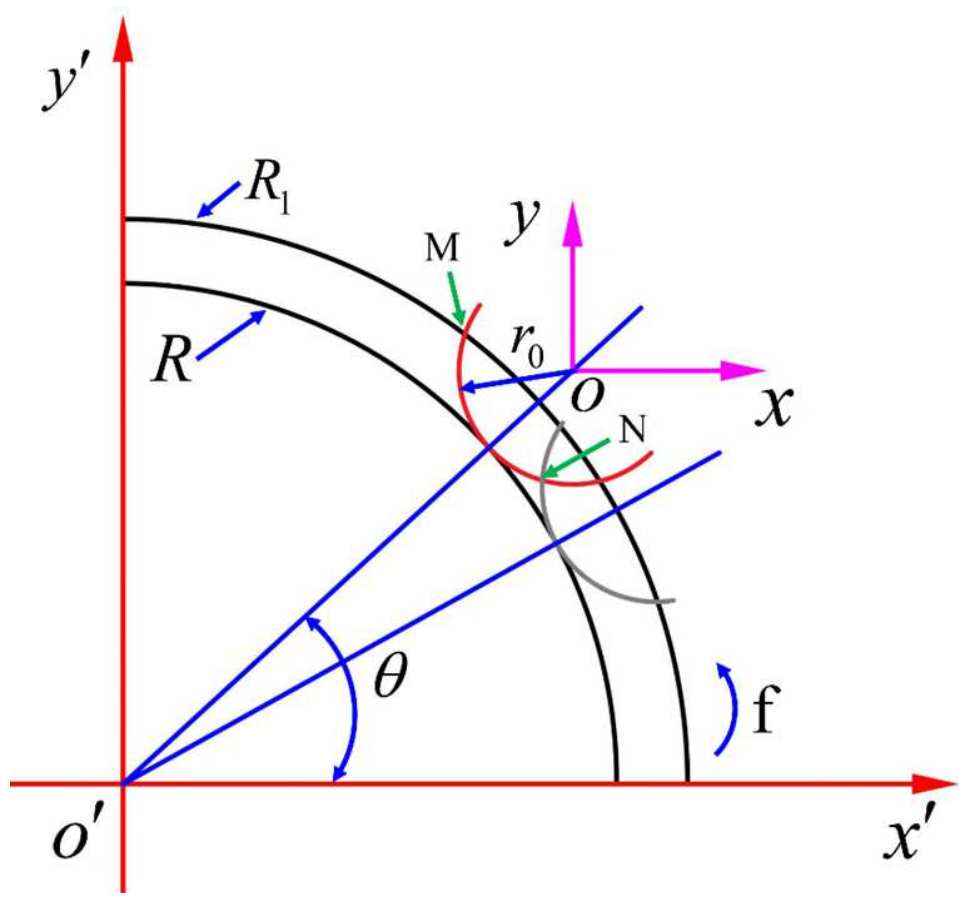

Fig. 5 Theoretical position of major notch and minor notch in the coordinate system

By substituting the theoretical position movement model of major notch and minor notch, and the relevant parameters $\left(r_{0}=0.2 \mathrm{~mm} ; R_{1}=100 \mathrm{~mm} ; \mathrm{R}=99.9 \mathrm{~mm}\right)$ into MATLAB, it can be shown that major notch and minor notch pass along tool nose arc and have an overlap area, as shown in Fig. 6. Notch wear is the key factor that contributes to tool failure, so the overlap area is the maximum wear area of carbide tools when turning the spherical shell. According to the wear characteristics of the turning spherical shell in Fig. 3, it can be found that the wear in the middle of the flank wear band is relatively larger, which is consistent with this model. This model also 
illustrates the flank wear land formation mechanism when turning the spherical shell. The wear land across the entire cutting edge occurs due to the movement of major notch and minor notch.

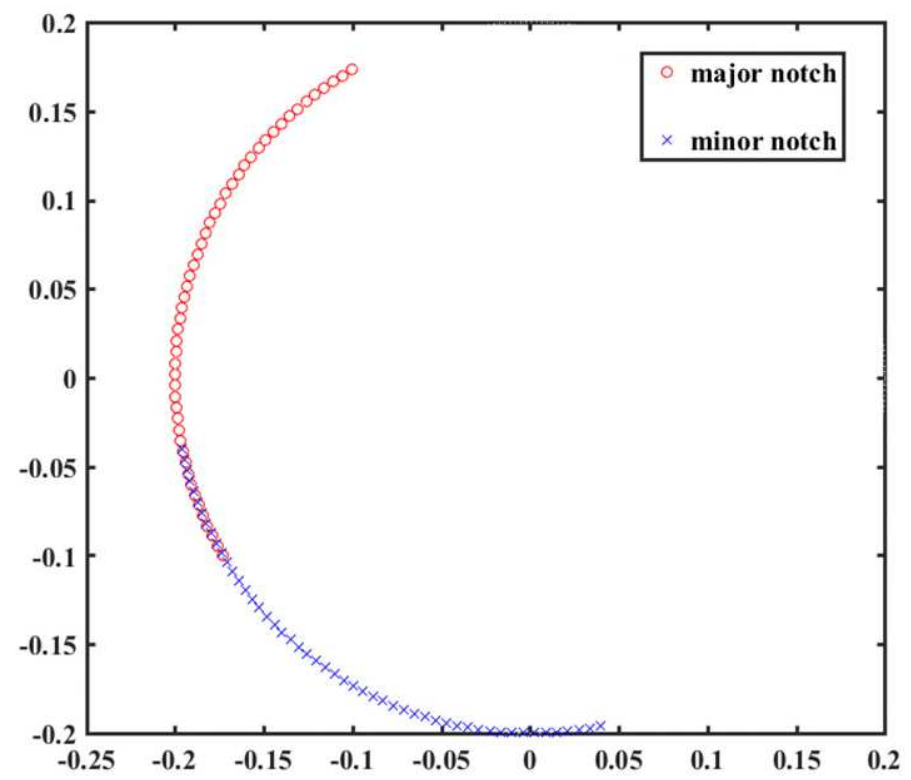

Fig. 6 Theoretical position trajectory of major notch and minor notch

\subsection{Tool wear evolution in turning curved surface of pure iron}

Actually, the tool wear is mostly characterized by the average flank wear. To better understand the law of tool degradation, the tool wear is comprehensively characterized by the cutting edge radius (CER), the flank wear (VB) and tool nose deterioration and corner radius. The tool edge degradation laws provide guidance on the effect of tool wear on surface accuracy during turning pure iron curved surface.

The measured tool wear as a function of cutting time is shown in Fig. 7 and Fig. 8. Major notch wear and minor notch wear increase with the cutting time when turning the end face, and major notch wear and minor notch wear are larger than the average flank wear. By turning spherical shell, the notch wear disappears, but the flank wear is about twice that by turning the end face, which verifies that the aforementioned mathematical model is reasonable. As the contact position of the tool-workpiece moves constantly while turning spherical shell, notch wear at the cutting boundary may travel along tool nose arc as well. Therefore, flank wear of turning spherical shell is larger than that of turning end face. Tool flank often rubbed with the contact boundary of the tool-workpiece when turning pure iron end face. Tool materials are pulled out easily due to tool strength descent. The cutting contact area doesn't move only within the feed per revolution when turning spherical shell, which makes tool wear at contact boundary of the tool-workpiece smaller. Therefore, flank wear of turning spherical shell is smaller than notch wear of turning end face. 


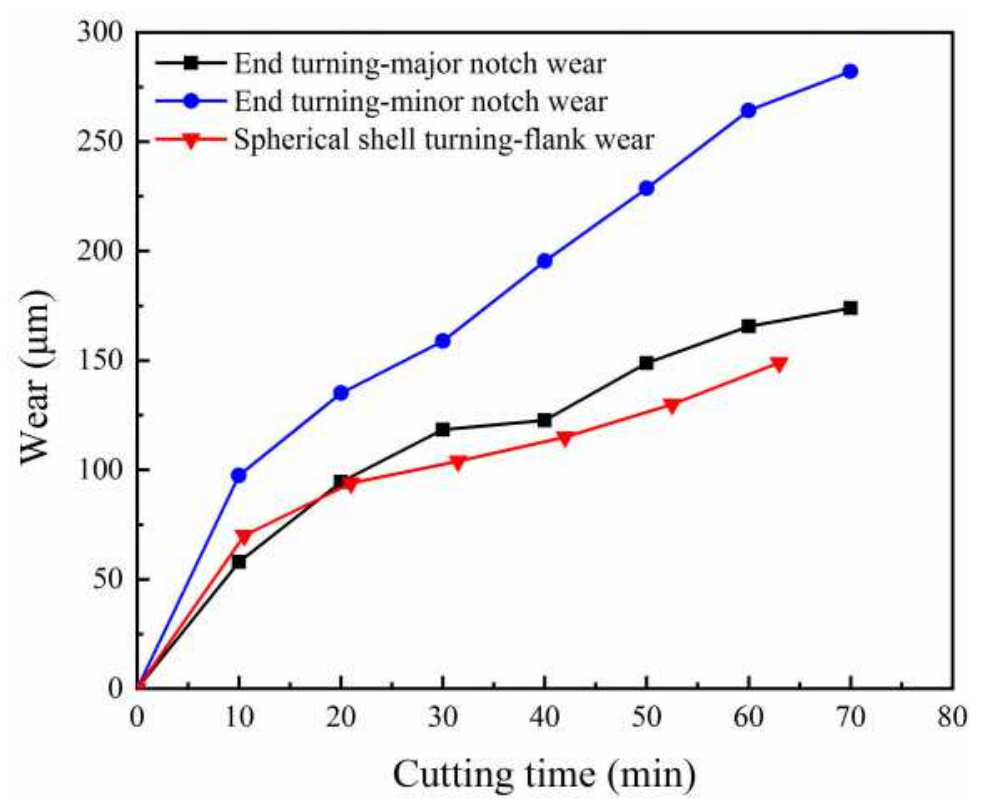

Fig. 7 Notch wear and flank wear during turning end face and spherical shell

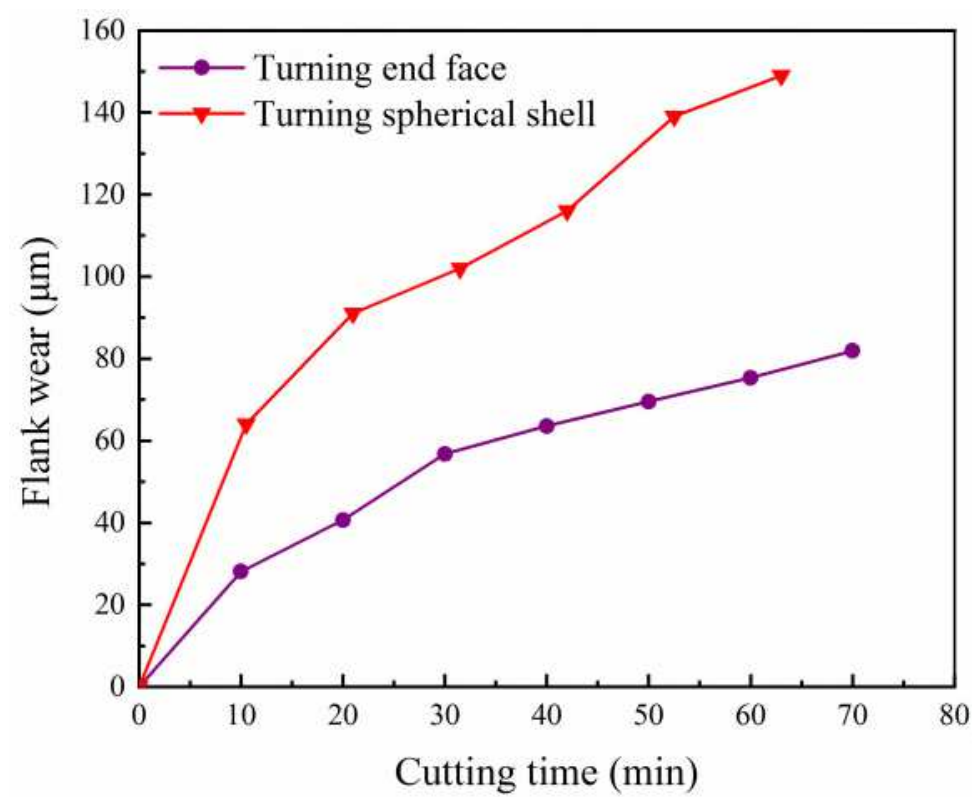

Fig. 8 Flank wear during turning end face and spherical shell

Variation of flank wear affects cutting edge radius (CER), cutting edge retraction, and tool nose radius. It has been known that cutting edge radius represents the tool's sharpness and directly influences process forces and cutting temperature[20,21]. CER variations in the cutting process are depicted in Fig. 10(a). At the early stage of cutting, the cutting edge of the new tool is sharp and low in strength. The contact area between the cutting edge and workpiece is very small. Therefore, the cutting edge is subject to heavy loads, which causes a large initial wear rate. Tool materials may fall away because of attrition. The cutting edge gradually becomes dull. CER tends to increase before cutting for 50 minutes. $S_{\alpha}$ is related to flank wear, and $S_{\alpha}$ can influence the size of material stagnation zone and the material separation point. The more material that flows under the flank face, the greater the friction between the flank face and the machined surface[22]. The flank face is squeezed and rubbed by the elastic-plastic deformation layer, causing the flank face to rapid wear. As shown in Fig 9, the profile of cutting edge shows a great loss of flank face 
material, and serious flank wear results in the edge tip moving toward the rake face. The edge profile indicates that the flank wear acts as the grinding tool and re-sharpens the cutting edge tip[23]. Therefore CER tends to decrease after cutting for 50 minutes.

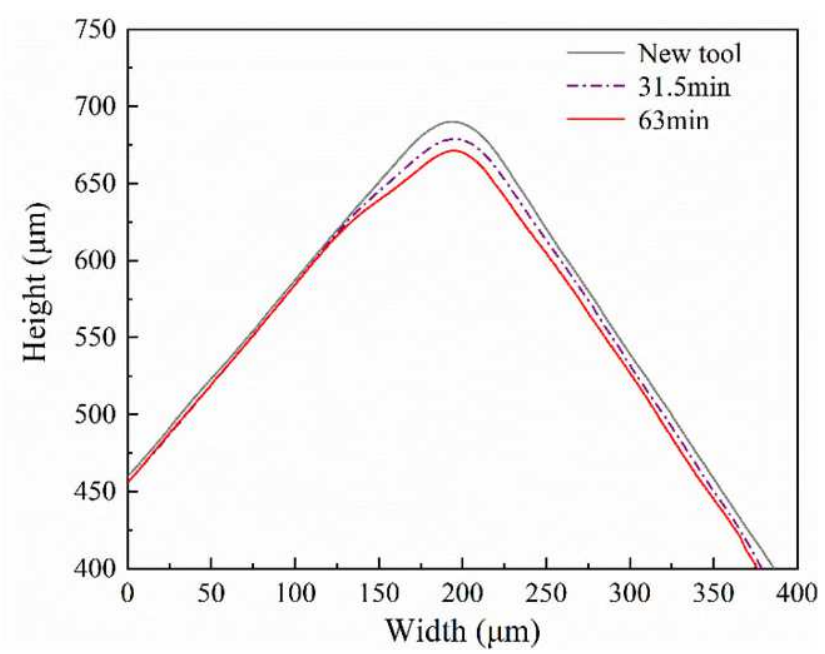

Fig. 9 Evolution of the cutting edge profile

Cutting edge retraction significantly affects the precision of curved components. Obtaining the values of cutting edge retraction can facilitate tool compensation when cutting curved parts, which can improve the machining accuracy of the parts. Cutting edge retraction gradually increases with cutting time in Fig 9 and Fig. 10(b). Cutting edge retraction indicates a noticeable increase in turning for $10 \mathrm{~min}$. It's due to the very sharp edge of the instrument and low strength. What's more, Fig. 11 indicates that the flank face is constantly worn, causing the tool nose to continuously retract along the radial direction of the tool nose arc. According to the relationship between flank wear and cutting edge retraction[24], severe flank wear of cutting spherical shell made cutting edge retraction greater.

According to tool imprints, tool nose radius is an important factor influencing the surface roughness. A bigger tool nose radius of worn cutting edge on the machined surface will lead to a smaller surface roughness[24]. Tool nose still maintains a circular arc shape due to notch wear disappears in Fig 12. Tool nose radius fluctuates around $215 \mu \mathrm{m}$ when cutting the spherical shell, as shown in Fig. 9(c). However, cutting edge retraction is continuously increasing, so tool nose arc is continuously degrading in the radial direction in turning spherical shell.

(a)

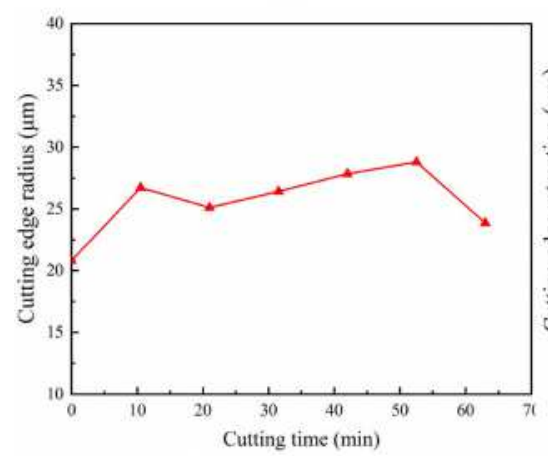

(b)

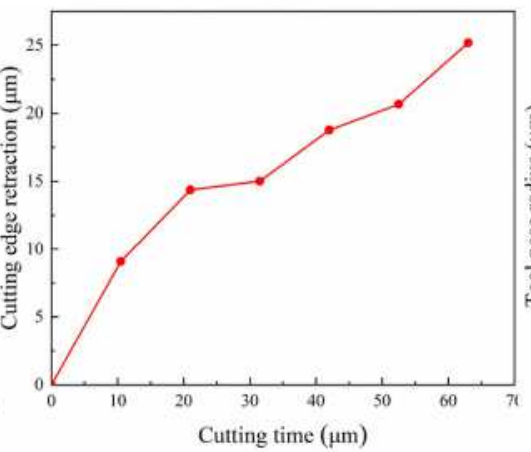

(c)

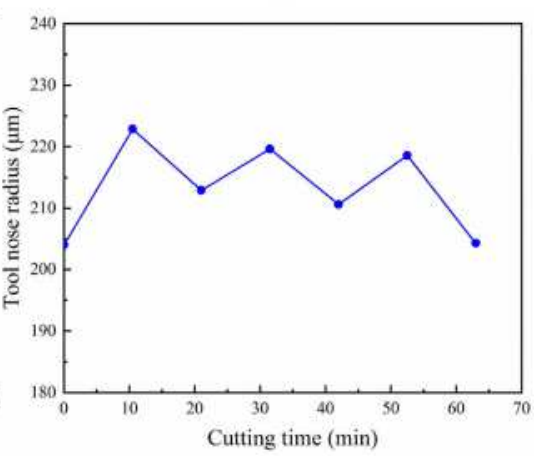

Fig. 10 Variation of CER(a), cutting edge retraction(b) and tool nose radius(c) during turning 


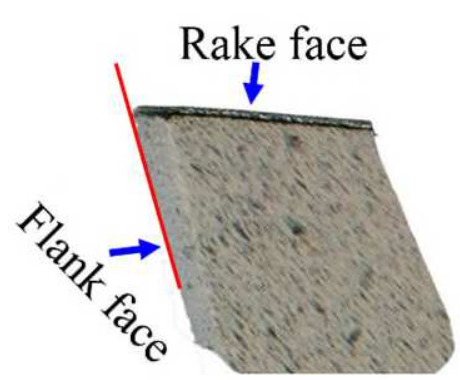

New tool

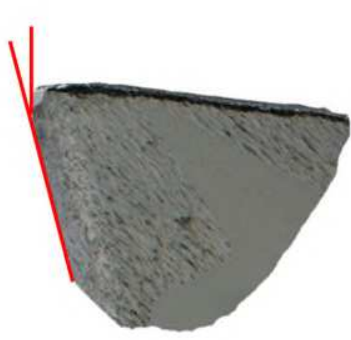

$21 \min$

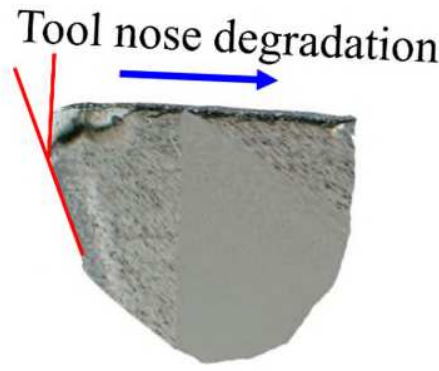

$63 \mathrm{~min}$

Fig. 11 Cutting edge retraction with the cutting time

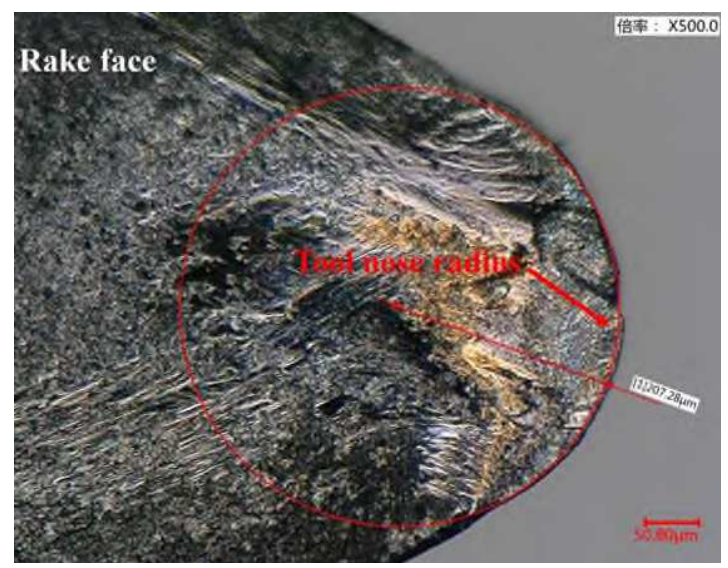

Fig. 12 Tool nose arc on rake face of turning pure iron spherical shell

\subsection{Tool wear mechanisms in turning curved surface of pure iron}

As mentioned earlier, by turning the spherical shell, the notch wear disappeared, and the flank wear was about twice that by turning the end face, which showed notch wear must participate in the formation of flank wear land. Hence, it could be inferred that the flank wear mechanism of turning spherical shell was basically the same as the notch wear mechanism of turning the end face. According to the EDS analysis results, it could be seen that pure iron materials adhered at the notch (Fig.13) and flank wear area(Fig.14). The pure iron materials were easily cold-welded on the tool under the high temperature and high pressure in the cutting area[8]. The pure iron materials bonded on tool surface would be plucked away by the action of chip flow or workpiece travel. As adhered pure iron materials peeled off, tool materials were also pulled out. Xue et al. regarded this process the adhering layer goes through as 'formation-stacking-plucking process' [25]. In addition, ambient air was easy to enter the cutting area. O element at tool wear area was observed in Fig.13 and Fig.14. serious oxidative wear occurred under promotion of high cutting temperature, especially at the tool-workpiece and tool-chip contact boundaries. W and Co in cemented carbide tools were main elements that are oxidized[16]. When TiAlN coating layer peeled off, $\mathrm{W}$ and Co were prone to be oxidized, which accelerated to the formation of softer oxidations. Fe in the workpiece and Co in the carbide tool matrix are homologous, so they have a strong affinity. Fe and Co could be almost completely dissolved at the high temperature[26,27], So 
they diffused easily with each other at the high temperature and pressure in the cutting area. In Fig.13 and Fig.14, the contents of Co were 5.03\% and 3.06\%. The Co content was lower than the standard content of new tool. Co was the binder of cemented carbide tools. Diffusion of Co weakened the adhesive strength among the carbide particles (WC), which made tool materials pulled out easily. At the same time, $\mathrm{Fe}$ in the adherent layer and the workpiece also diffused into the binder phase (Co) of cutting tool by means of grain boundary diffusion to break tool structure[25-27]. Fe was oxidized easily, which accelerated the formation of oxidation such as $\mathrm{Fe}_{2} \mathrm{O}_{3}$ and $\mathrm{Co}_{2} \mathrm{O}_{4}[26]$. Where the iron content was high, the oxygen content was also high, as shown in Fig.13 and Fig.14. The diffusion and oxidation weakened tool strength, which resulted in tool materials being pulled out under the combined actions of scratching and attrition.

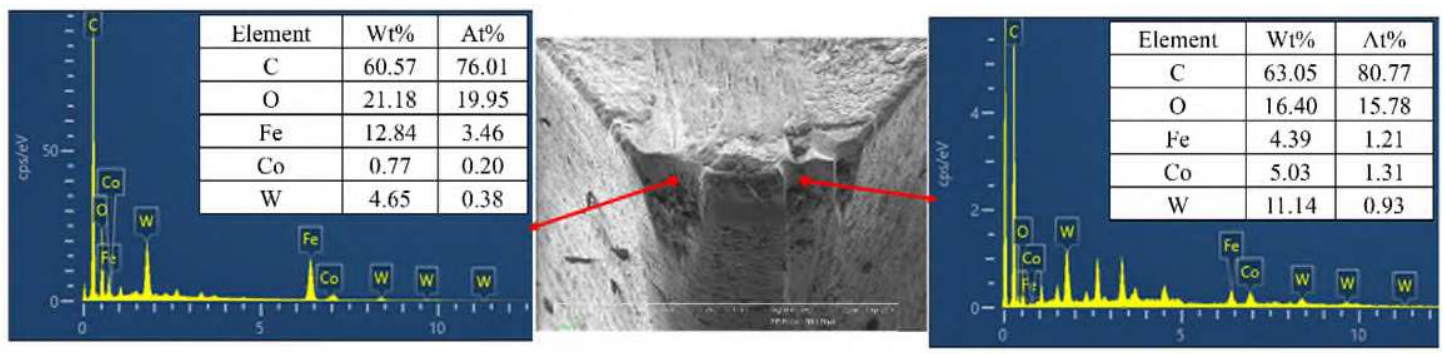

Fig.13 EDS analysis results of turning end face

Flank wear land
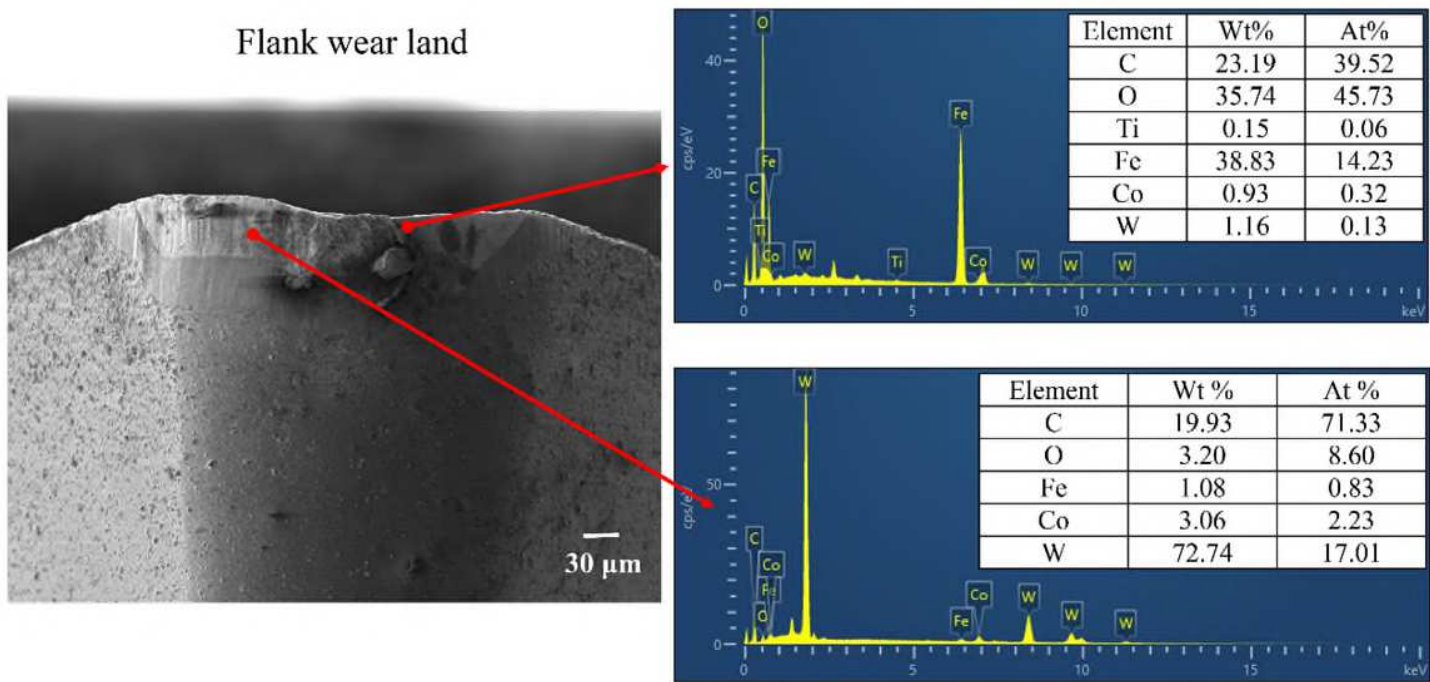

Fig. 14 EDS analysis results of turning spherical shell

Therefore, flank wear mechanisms of coated carbide tools included adhesive wear, diffusion wear, and oxidation wear when turning spherical shell, which was consisitent with notch wear mechanisms. But these factors are not independent, instead one wear mechanism tends to trigger another[8].

\section{Conclusions}

This research explored tool wear characteristics in finish turning pure iron curved surface. The following conclusions can be drawn.

(1) The main wear modes during end faces turning of pure iron material are flank wear and severe major notch wear and minor notch wear. However, severe notch wear disappears and only flank wear land along the tool nose occurs during spherical shell turning of pure iron material. 
Aforementioned difference of wear modes is caused by the continuous movement of the tool-workpiece contact position during turning curved surface.

(2) A mathematical model is developed to explain formation mechanisms of flank wear characteristics in turning of pure iron spherical shell. The flank wear land results from the movement of major notch position and minor notch position, and the overlap area of major notch position and minor notch position is the maximum wear area.

(3) The flank wear of turning spherical shell is larger than that of turning end face, but smaller than notch wear of turning end face. It verifies that the mathematical model is reasonable. Due to serious flank wear, the cutting edge radius tends to increase first and then decrease.Cutting edge retraction gradually increases with the cutting time, but tool nose radius are basically unchanged. Therefore, tool tip retracts along the radial direction of tool nose arc.

(4) Flank wear mechanisms are the result of the combined effects of adhesion wear, diffusion wear, and oxidation wear during turning spherical shell of pure iron materials. It is consistent with notch wear mechanisms of turning end face.

\section{Declarations}

\section{Ethics approval}

Not applicable.

\section{Consent to participate}

All authors have approved to participate.

\section{Consent for publication}

The manuscript is approved by all authors for publication.

\section{Declaration of Competing Interest}

The authors declare that they have no known competing financial interests or personal relationships that could have appeared to influence the work reported in this paper.

\section{Author Contributions}

Design of the work and methodology, Yu Chen; investigation and writing-original draft preparation, Jinxing Kong; Data curation, Dongxing Du; conceptualization, review and editing, Zhenyu Zhang. All authors have read and agreed to the published version of the manuscript.

\section{Availability of data and material}

All data generated or analysed during this study are included in this published article.

\section{Acknowledgements}

This work was supported by the National Natural Science Foundation of China, No. 51805498, the Science Challenge Project, No. JDZZ2016006-0105-01, and the Key Laboratory of ultra-precision-machining of CAEP, No. ZM18003. 


\section{Reference}

1. Chen YT, Tang XJ, Li QZ (2010) Shock-induced phase transition and spalling characteristic in pure iron and FeMnNi alloy. Chin Phys B 19(5):1-8

2. Ferrara E, Olivetti E, Fiorillo F, Forton E, Martino L, Rocchino L (2014) Microstructure and magnetic properties of pure iron for cyclotron electromagnets. J Alloys Compd 615:291-295

3 Jiang S, Yan S, Liu Y, Duan C, Xu J, Sun Y (2019) Analytical prediction of chatter stability in turning of low-stiffness pure iron parts by nosed tool. Int J Adv Manuf Technol 102:1227-1237

4. Narulkar R, Bukkapatnam S, Raff L, Komanduri R (2008) Graphitization as a precursor to wear of diamond in machining pure iron: a molecular dynamics investigation. Comput Mater Sci 45: 358-366.

5.Rahman M, Kumar A, Prakash J (2011) Micro milling of pure copper. J Mater Process Technol 116:39-43.

6. Wang X (2012) A study of tool Wear in turning of pure aluminum and drilling of CFRP/titanium stacks. Michigan State University. Mech Eng

7. Xu D M , Chen H , Kong J X (2013) Study on application of lubrication technology in turning pure iron. Mater Sci 770:116-119

8. Kong J, Xia Z, Xu D, He N (2016) Investigation on notch wear mechanism in finish turning pure iron material with uncoated carbide tools under different cooling/lubrication conditions. Int $\mathrm{J}$ Adv Manuf Technol 86:97-105

9. Tao H, Su GS, Feng LM, et al. (2019) Experimental Study on Tool Wear of Different Materials in Pure Iron Turning. J Qilu Univ Technol 33(3):54-61.

10. Liu X , Zhang F , Liu J , et al.(2020) Atmospheric pressure plasma-assisted precision turning of pure iron material. Int J Adv Manuf Technol 106(4):1-11.

11. Xiao MH, He N, Li L (2010) Modeling notch wear of ceramic tool in high speed machining of nickel-based superalloy. J Wuhan Univ Technol-Mater 25(1):78-83.

12. He N, Pan LX, Zhang YZ (1995) Notch wear of machining nickel based alloys with ceramic tools. Chin J Mech Eng 8(4):262-266

13. Bushlya V, Zhou J, Avdovic P, Ståhl J-E (2013) Wear mechanisms of silicon carbide-whisker-reinforced alumina $(\mathrm{Al} 2 \mathrm{O} 3-\mathrm{SiCw})$ cutting tools when high-speed machining aged alloy 718. Int J Adv Manuf Technol 68(5-8):1083-1093

14. Ezugwu EO, Wang ZM, Machado AR (1999). The machinability of nickel-based alloys: a review. J Mater Process Technol. 86(1-3):1-1

15. Brandt G, Gerendas A, Mikus M (1990) Wear mechanisms of ceramic cutting tools when machining ferrous and non-ferrous alloys. J Eur Ceram Soc. 6(5):273-290.

16. Olovsjö S, Nyborg L (2012) Influence of microstructure on wear behaviour of uncoated WC tools in turning of Alloy 718 and Waspaloy. Wear 282-283:12-21

17. Zhuang KJ, Zhu DH, Zhang XM, Ding H (2014). Notch wear prediction model in turning of inconel 718 with ceramic tools considering the influence of work hardened layer. Wear 313(1-2):63-74

18. Kasim M S , Che Haron C H , Ghani J A et al(2013) Wear mechanism and notch wear location prediction model in ball nose end milling of Inconel 718. Wear 302(1-2):1171-1179. 
19. Akhtar W , Sun J, Sun P et al (2014) Tool wear mechanisms in the machining of Nickel based super-alloys: A review. Front Mech Eng 9(2):106-119.

20. Özel T, Zeren (2007). Finite element modeling the influence of edge roundness on the stress and temperature fields induced by high-speed machining. Int J Adv Manuf Technol 35:255-267

21. Kai Y, Liang Y, Zheng K, Bai Q, Chen W (2011) Tool edge radius effect on cutting temperature in micro-end-milling process. Int J Adv Manuf Technol 52:905-912.

22. Denkena B, Köhler J, Mengesha M (2012) Influence of the cutting edge rounding on the chip formation process: part 1. investigation of material flow, process forces, and cutting temperature. Prod Eng, 6:329-338.

23. Wang F, Qian B, Jia, Z, Fu R, Cheng D (2017) Secondary cutting edge wear of one-shot drill bit in drilling CFRP and its impact on hole quality. Compos Struct. 178:341-352.

24. Zhang G, To S, Zhang S (2016) Evaluation for tool flank wear and its influences on surface roughness in ultra-precision raster fly cutting. Int J Mech Sci 118:125-134

25. Xue C, Chen W (2011). Adhering layer formation and its effect on the wear of coated carbide tools during turning of a nickel-based alloy. Wear 270(11):895-902.

26. Hao ZP, Gao D, Fan, YH , Han, RD (2011). New observations on tool wear mechanism in dry machining inconel718. Int J Mach Tools Manuf 51(12):973-979.

27. Liao Y S , Shiue R H (1996) Carbide tool wear mechanism in turning of Inconel 718 superalloy. Wear 193(1):16-24. 


\section{Figures}
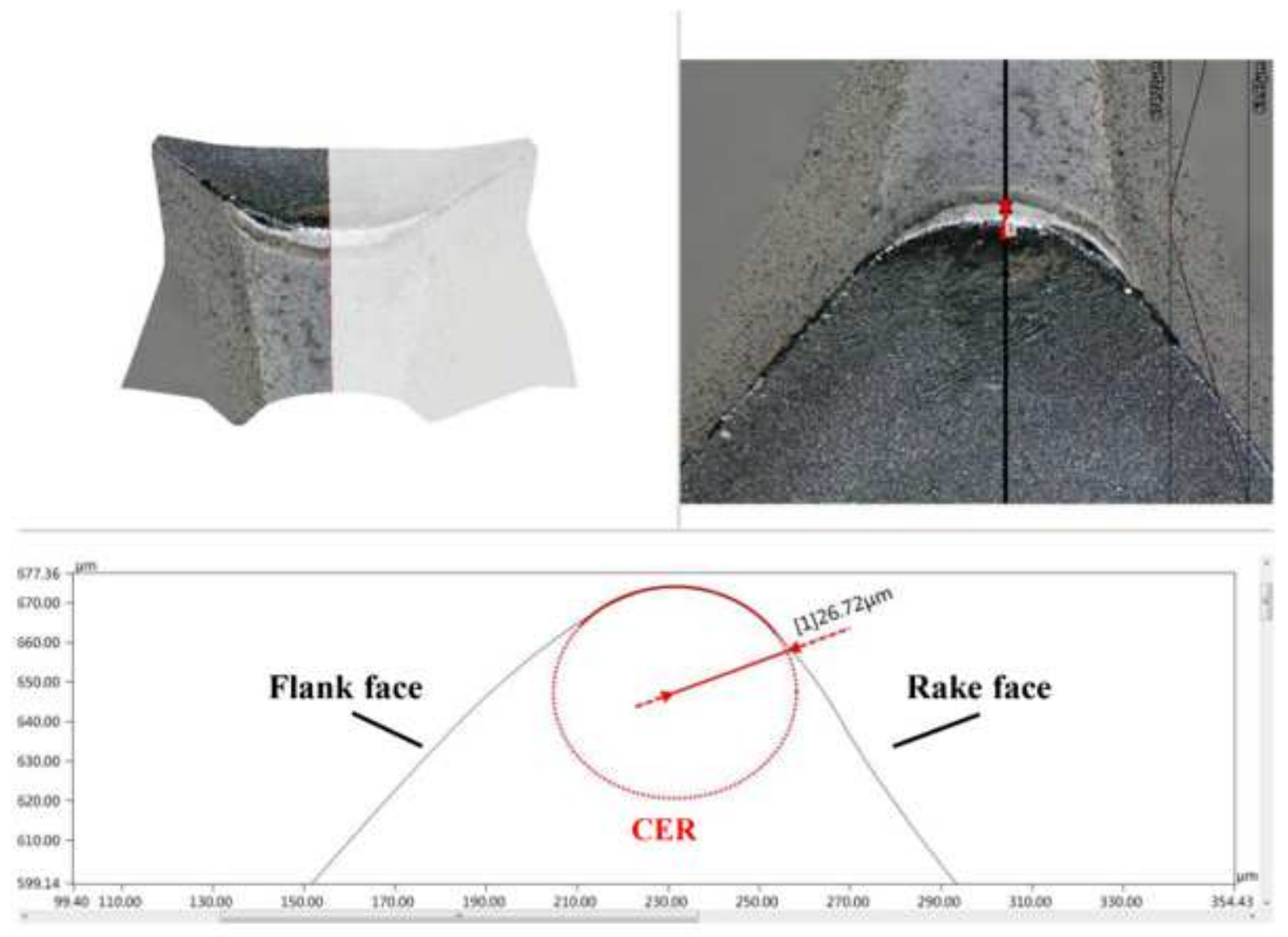

Figure 1

2D profile of secondary cutting edge obtained by microscope.
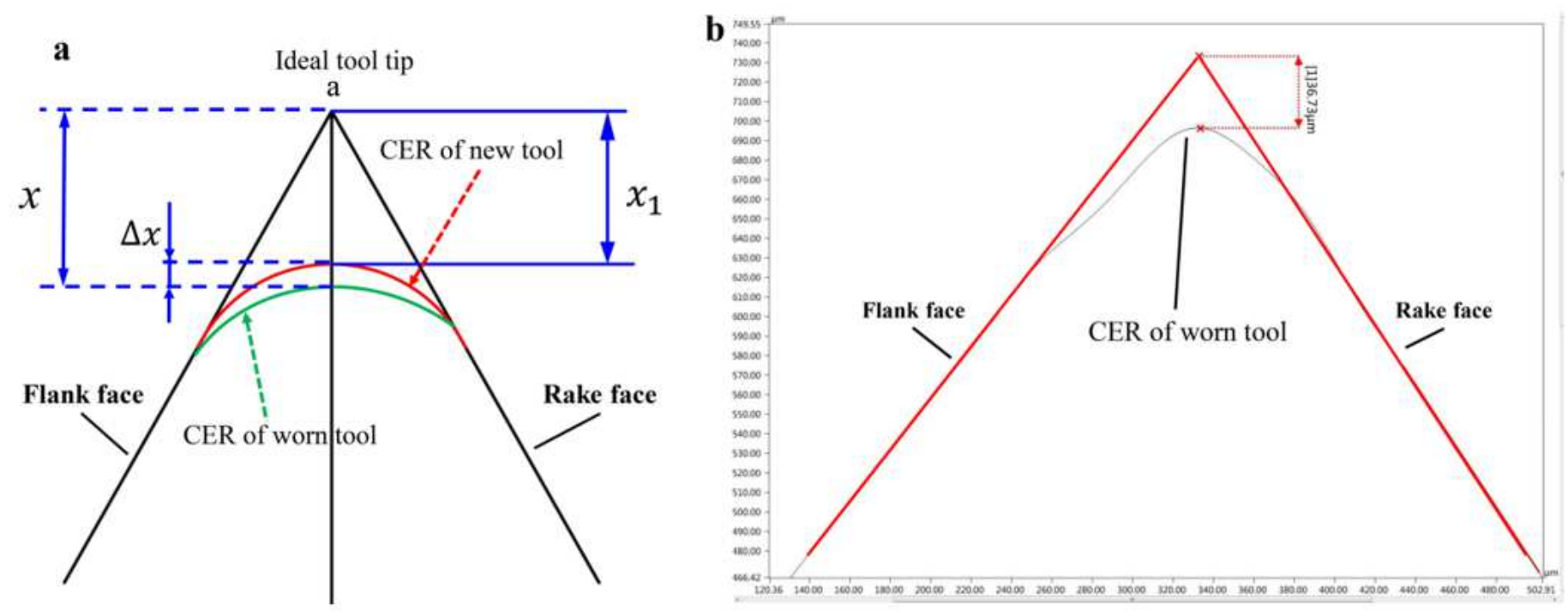

Figure 2 
(a) Schematic of cutting edge retraction measurement and (b) distance between the ideal tool tip and actual tool tip

(a)
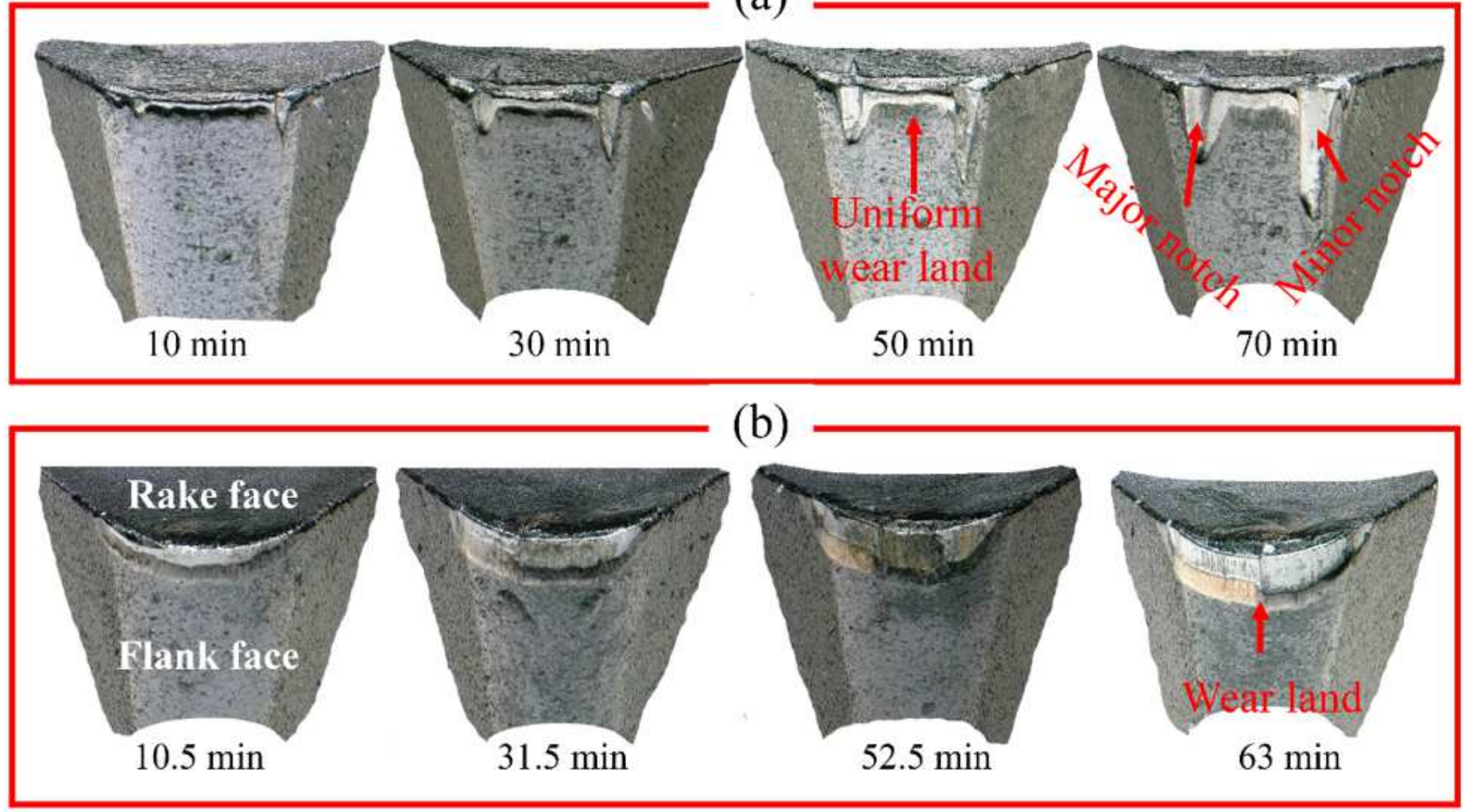

Figure 3

Comparison of tool wear under different cutting methods, (a) end face turning, (b) spherical shell turning 

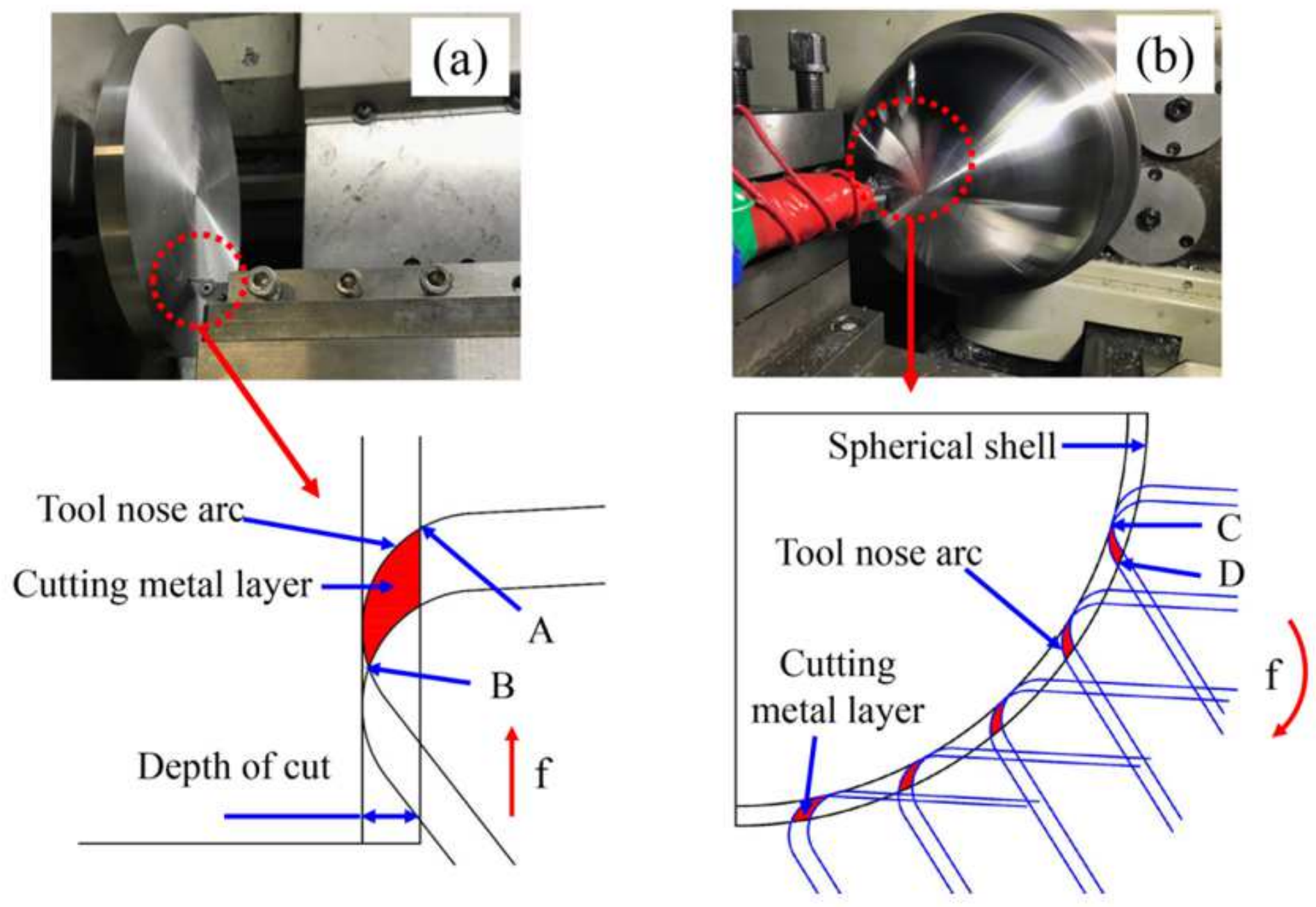

Figure 4

Schematic of turning end face (a) and turning spherical shell (b) 


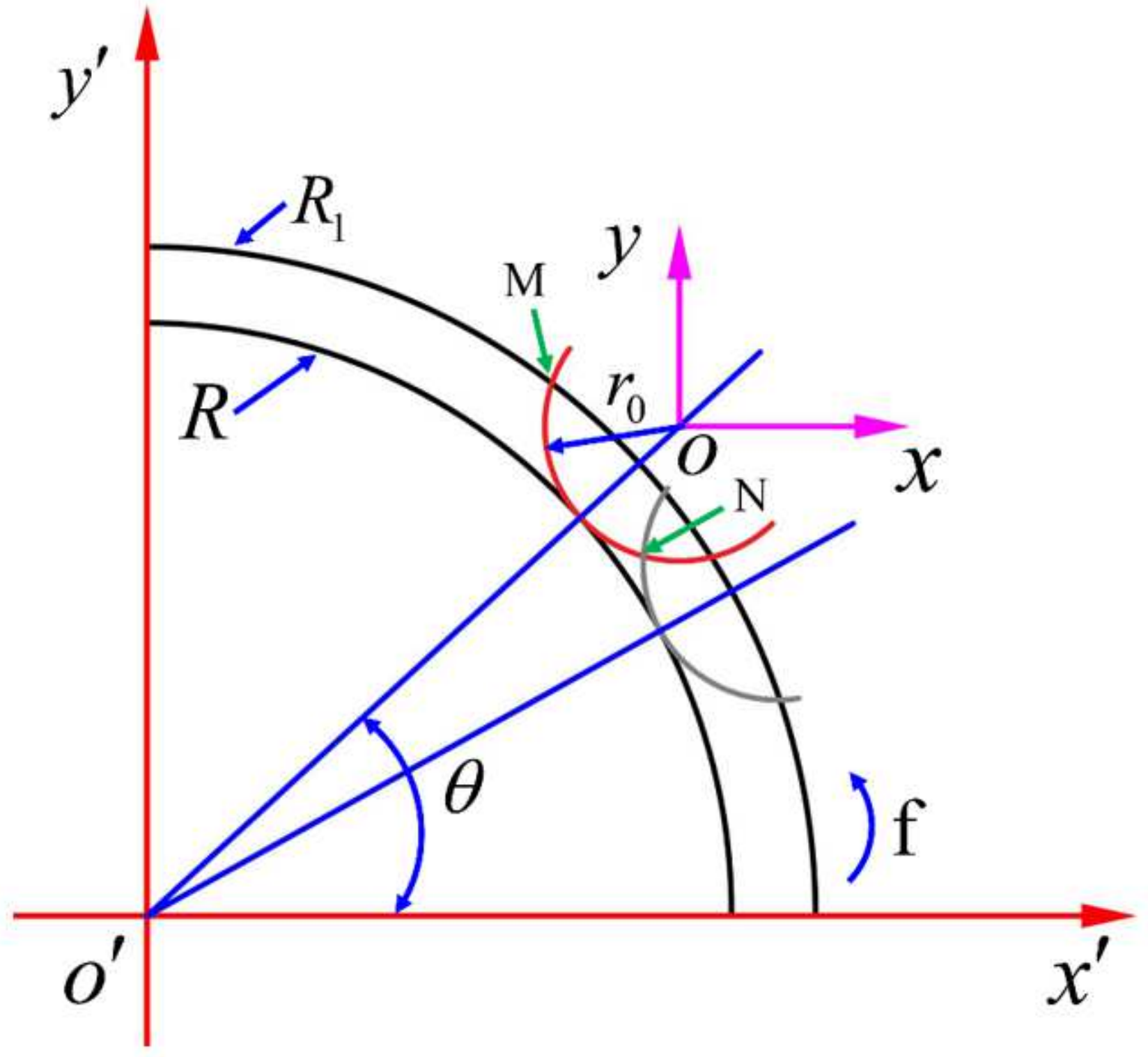

Figure 5

Theoretical position of major notch and minor notch in the coordinate system 


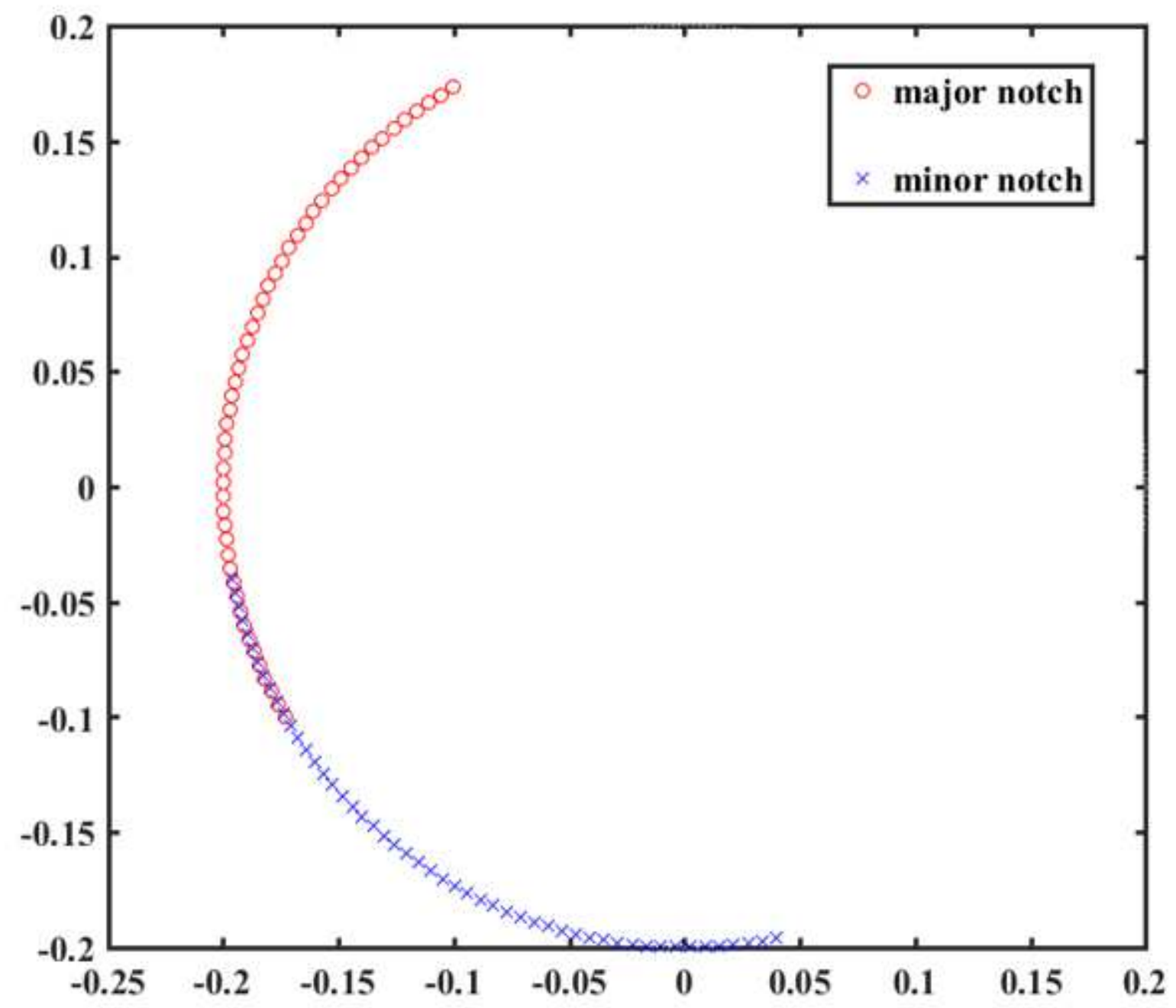

Figure 6

Theoretical position trajectory of major notch and minor notch 


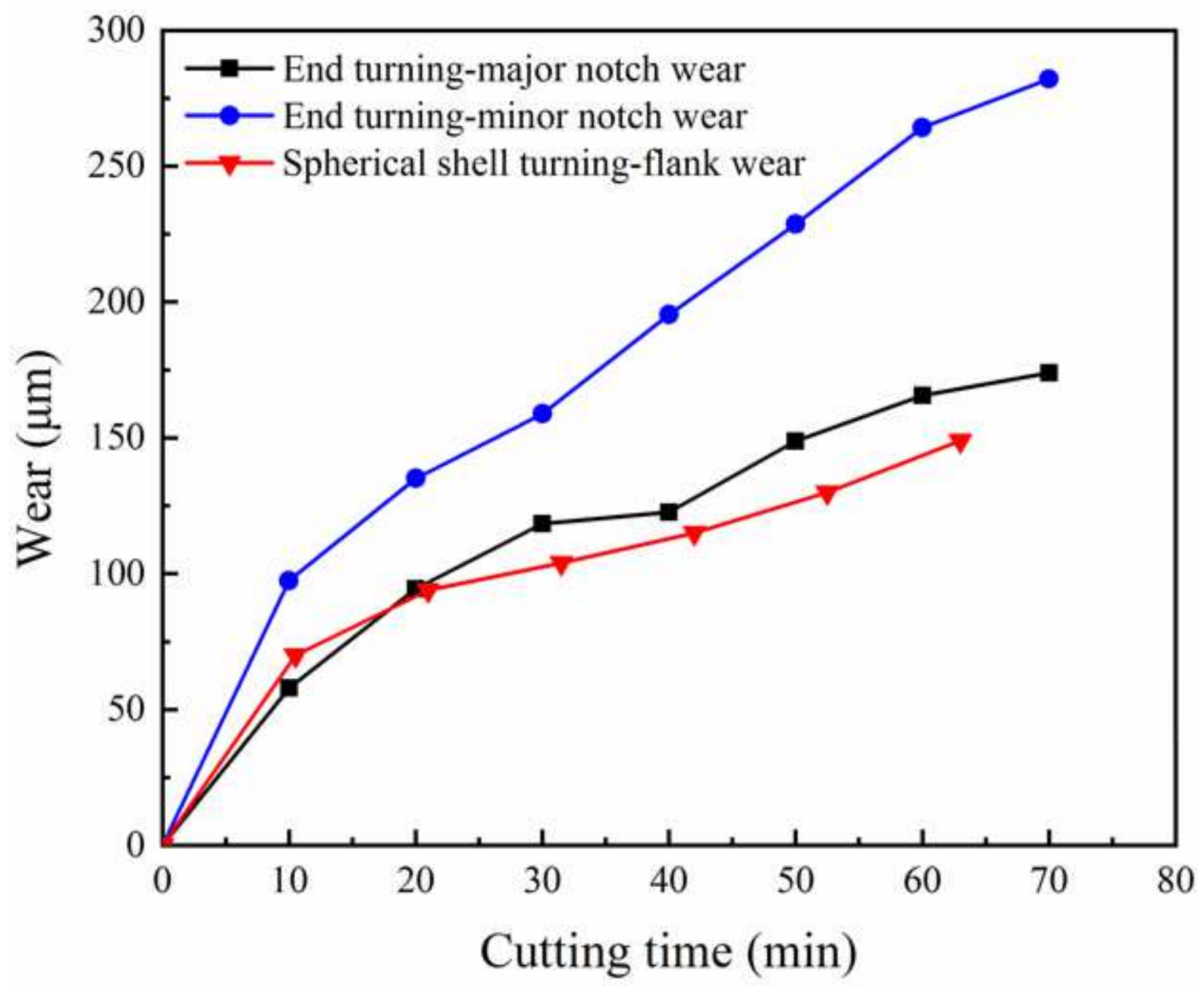

Figure 7

Notch wear and flank wear during turning end face and spherical shell 


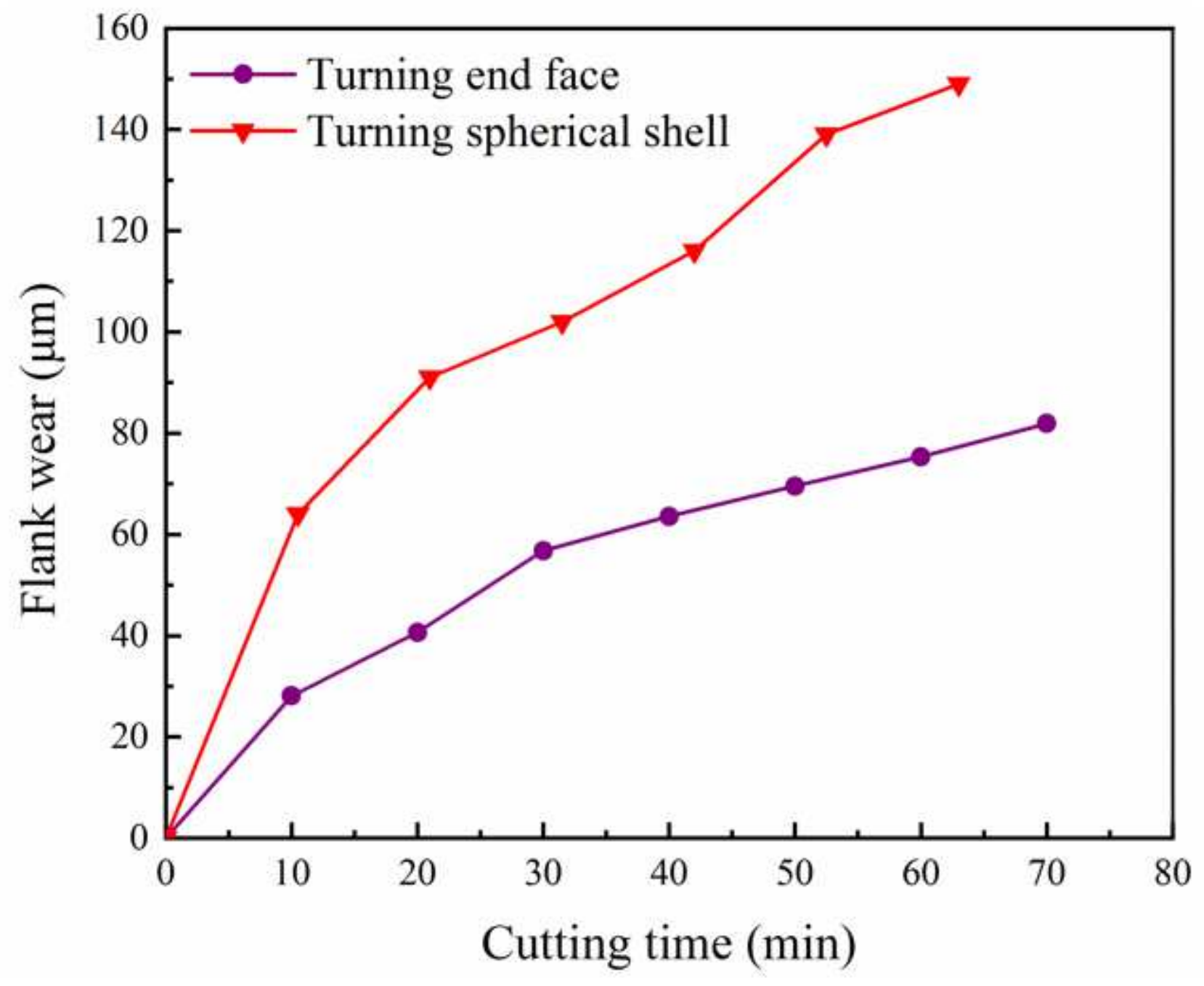

Figure 8

Flank wear during turning end face and spherical shell 


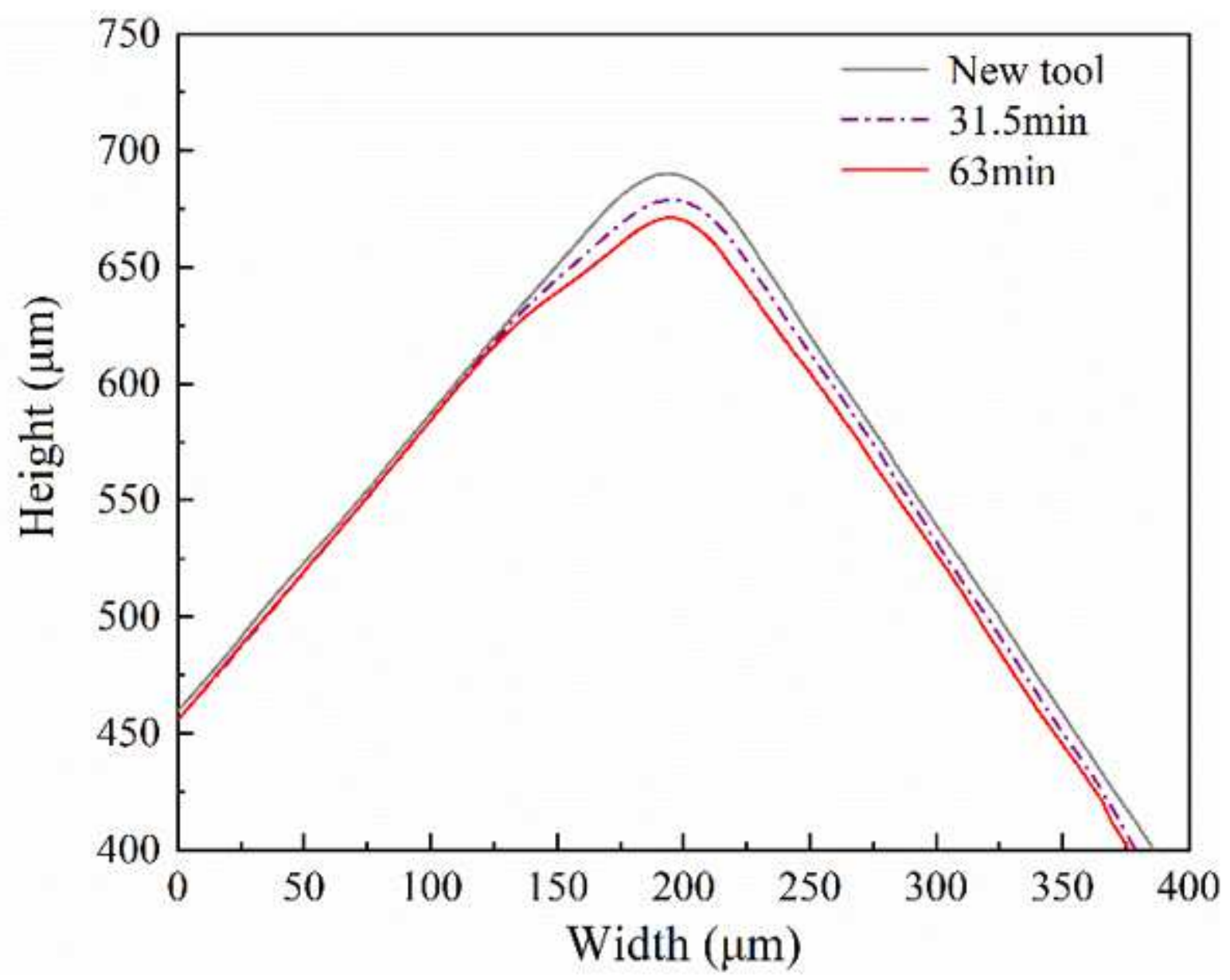

Figure 9

Evolution of the cutting edge profile

(a)

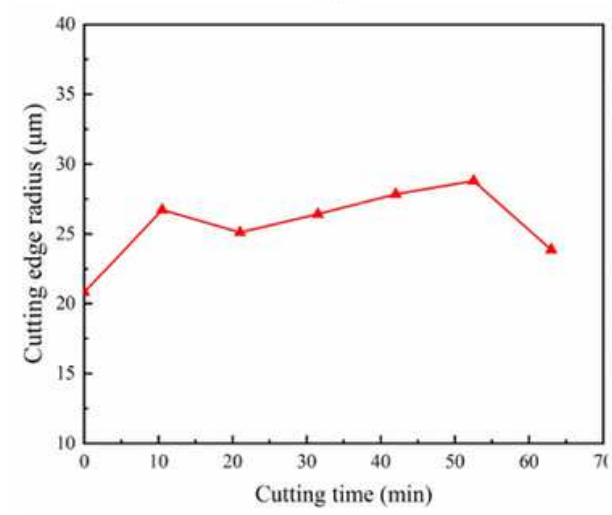

(b)

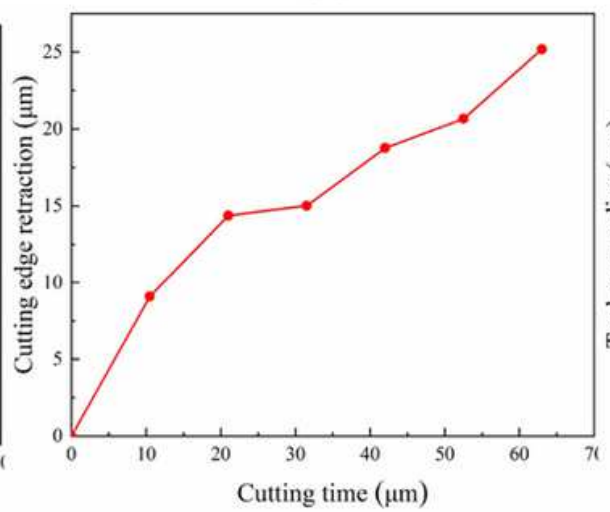

(c)

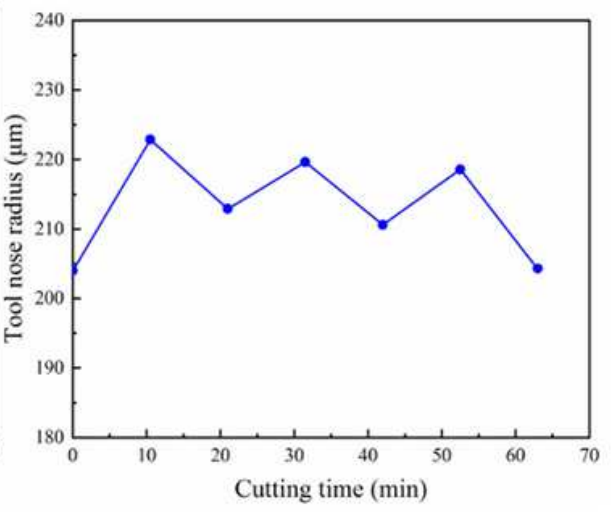

Figure 10

Variation of $\mathrm{CER}(\mathrm{a})$, cutting edge retraction(b) and tool nose radius(c) during turning 
spherical shell

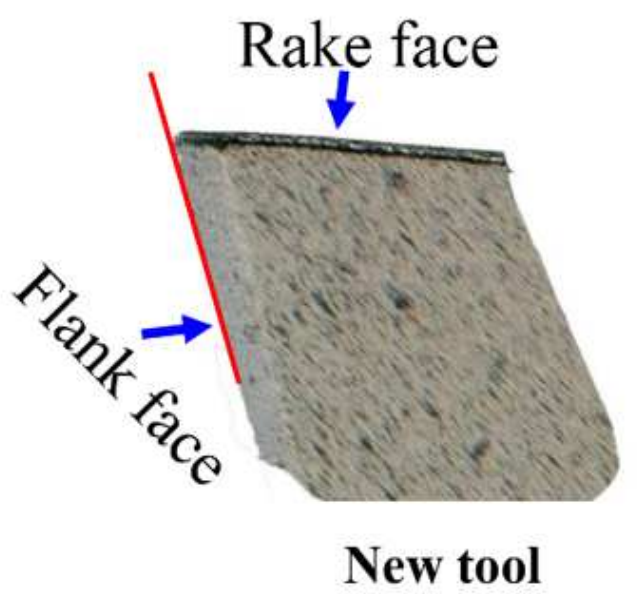

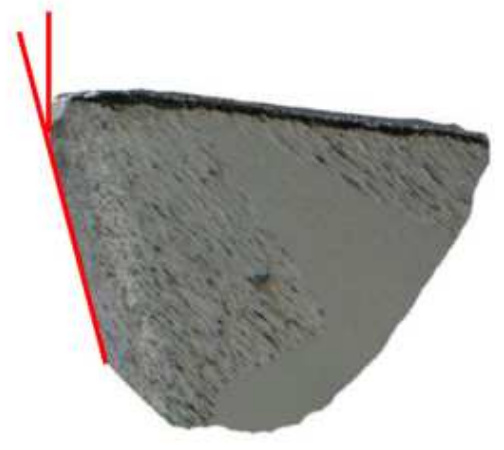

$21 \mathrm{~min}$

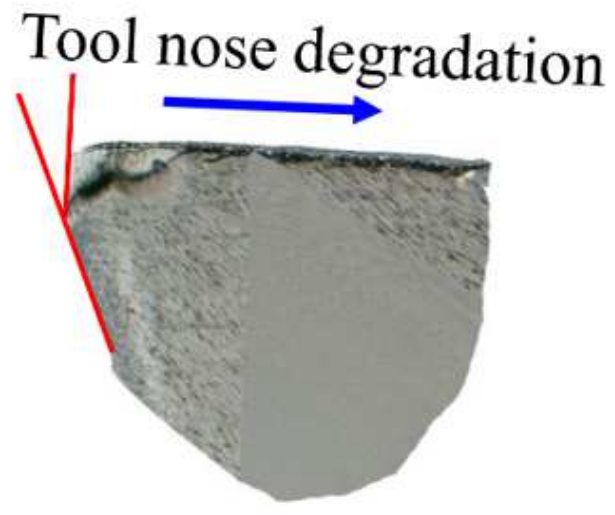

$63 \mathrm{~min}$

\section{Figure 11}

Cutting edge retraction with the cutting time

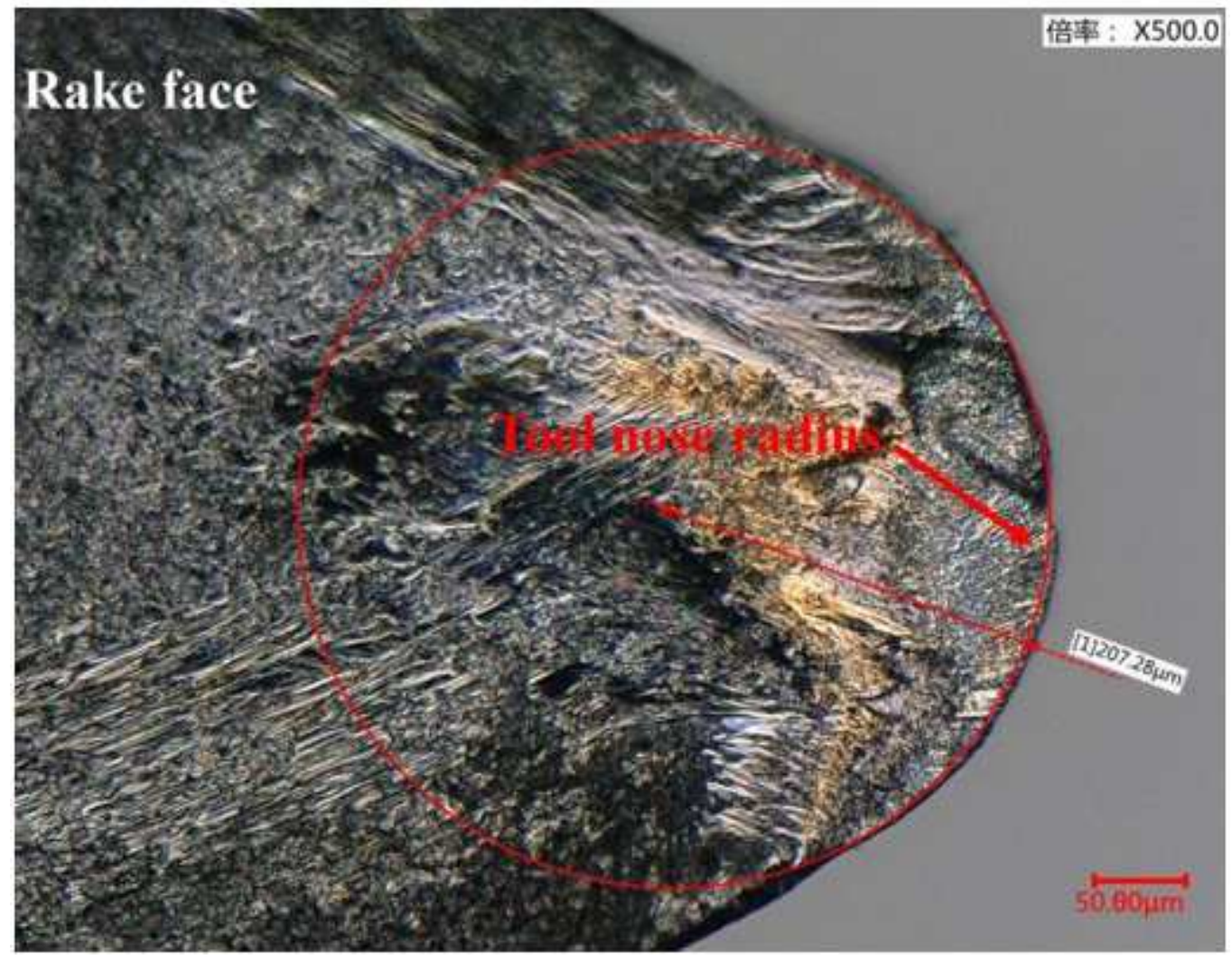

Figure 12

Tool nose arc on rake face of turning pure iron spherical shell 

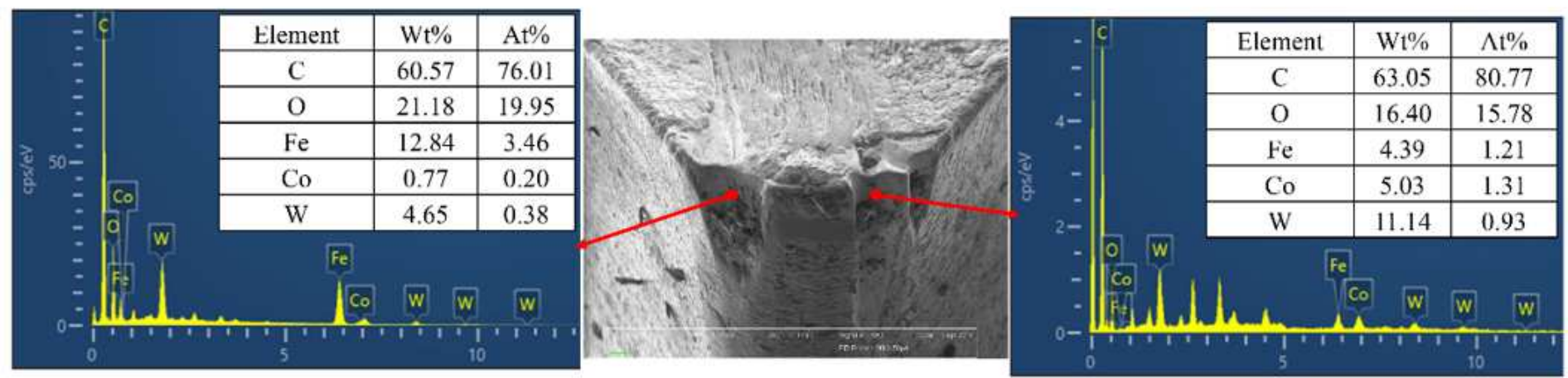

\section{Figure 13}

EDS analysis results of turning end face

Flank wear land
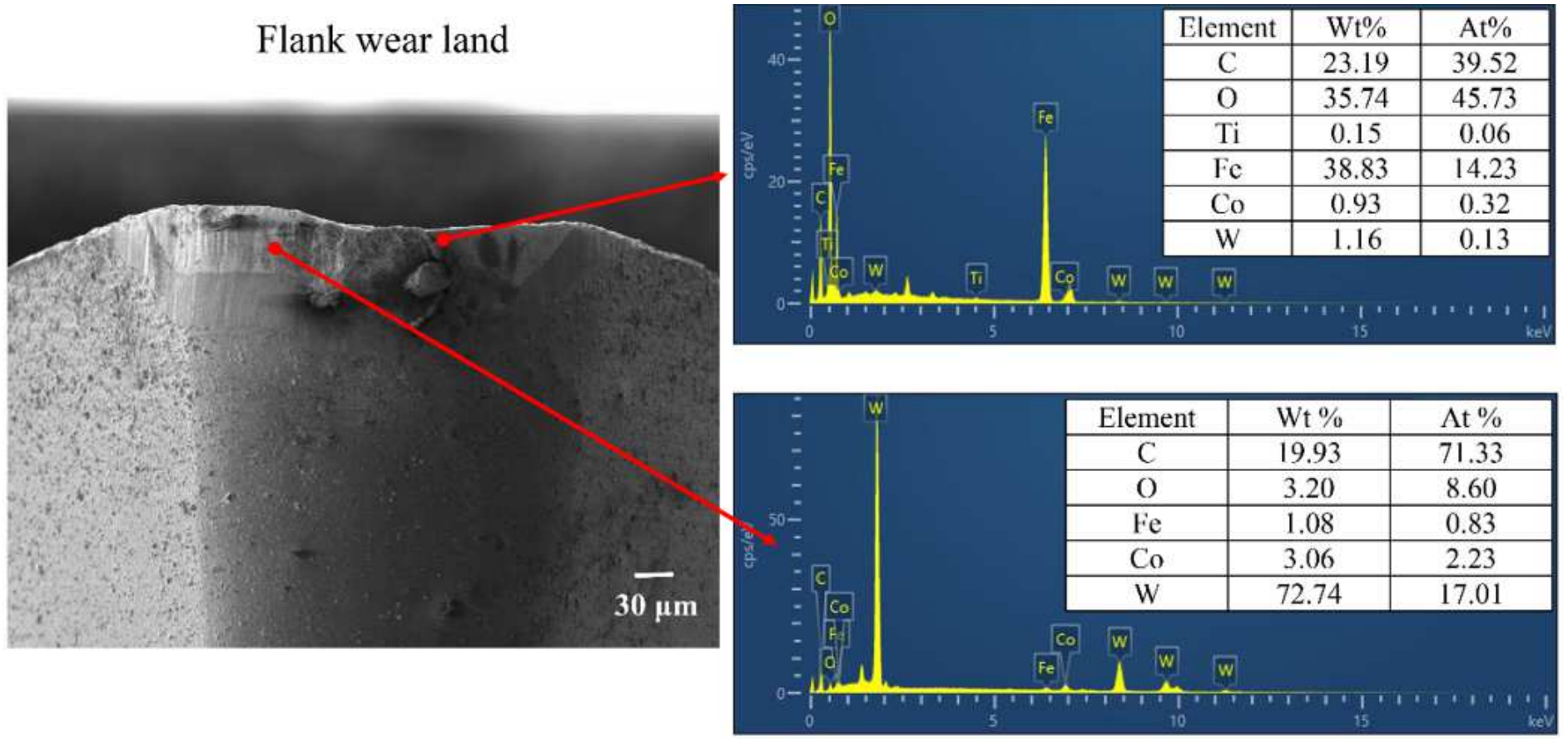

Figure 14

EDS analysis results of turning spherical shell 